\title{
Nitrate vulnerability projections from Bayesian inference of multiple groundwater age tracers
}

Authors: Jamal Alikhani ${ }^{1}$, Amanda Deinhart ${ }^{2,3}$, Ate Visser $^{2}$, Richard Bibby ${ }^{2}$, Roland Purtschert ${ }^{4}$, Jean Moran $^{3}$, Arash Massoudieh ${ }^{1}$, Brad Esser ${ }^{2}$

1- Department of Civil Engineering, The Catholic University of America, Washington, DC

2- Lawrence Livermore National Laboratory, Livermore, California

3- Department of Earth and Environmental Sciences, California State University, East Bay

4- Climate and Environmental Physics, University of Bern, Bern, Switzerland.

\section{Abstract}

Nitrate is a major source of contamination of groundwater in the United States and around the world. We tested the applicability of multiple groundwater age tracers $\left({ }^{3} \mathrm{H},{ }^{3} \mathrm{He},{ }^{4} \mathrm{He},{ }^{14} \mathrm{C},{ }^{13} \mathrm{C}\right.$, and $\left.{ }^{85} \mathrm{Kr}\right)$ in projecting future trends of nitrate concentration in 9 long-screened, public drinking water wells in Turlock, California, where nitrate concentrations are increasing toward the regulatory limit. Very low

${ }^{85} \mathrm{Kr}$ concentrations and apparent ${ }^{3} \mathrm{H} /{ }^{3} \mathrm{He}$ ages point to a relatively old modern fraction (40-50 years), diluted with pre-modern groundwater, corroborated by the onset and slope of increasing nitrate concentrations. An inverse Gaussian-Dirac model was chosen to represent the age distribution of the sampled groundwater at each well. Model parameters were estimated using a Bayesian inference, resulting in the posterior probability distribution - including the associated uncertainty -of the parameters and projected nitrate concentrations. Three scenarios were considered, including combined historic nitrate and age tracer data, the sole use of nitrate and the sole use of age tracer data. Each scenario was evaluated based on the ability of the model to reproduce the data and the level of reliability of the nitrate projections. The tracer-only scenario closely reproduced tracer concentrations, but not observed trends in the nitrate concentration. Both cases that included nitrate data resulted in good agreement with historical nitrate trends. Use ofcombined tracers and nitrate data resulted in a narrower range of projections of future nitrate levels. However, use of combined tracer and nitrate resulted in a larger discrepancy between modeled and measured tracers for some of the tracers. Despite nitrate trend slopes between 0.56 and $1.73 \mathrm{mg} / \mathrm{L} /$ year in 7 of the 9 wells, the probability that concentrations will increase to levels above the MCL by 2040 are over $95 \%$ for only two of the wells, and below $15 \%$ in the other wells, due to a leveling off of reconstructedhistorical nitrate loadings to groundwater since about 1990 .

\section{Introduction}

Rising nitrate concentrations in public supply wells present a serious threat to drinking water in California where wide-spread, long-term application of fertilizers is implicated as the primary cause of nitrate contamination to groundwater(Esser et al., 2002; Harter, 2012). In many key groundwater basins in California, a majority of deep supply wells have nitrate concentrations that are presently above natural, background levels but below the United States Environmental Protection Agency (USEPA) 
regulatory limit of $45 \mathrm{mg} / \mathrm{l}$ (as $\mathrm{NO}_{3}{ }^{-}$) (Belitz et al., 2015). The likelihood that nitrate resides in the vadose zone and shallow aquifer zones, but will gradually be transported to deeper aquifers, makes prediction of future trends in nitrate concentration of paramount interest. Long-screened public supply wells tend to capture a broad distribution of groundwater age and in many settings the age distribution determines the evolution of nitrate concentrations in produced groundwater (MacDonald et al., 2003; Wassenaar et al., 2006). Wells exhibiting very young apparent groundwater age are expected to show a rapid response to nitrate applications at the surface. Wells with intermediate ages may show a slower response and long term upward trends, which could continue upward for decades regardless of changes in land use or rates of fertilizer application. Wells dominated by old age distributions could show continueddilution of nitrate by water that is low in nitrate, allowing the possibility that wells will continue to produce water below the regulatory limit in the long term.

Methods for detecting and extrapolating trends in nitrate concentrations (Visser et al., 2009b)range from statistical regression based on historical trends (Batlle-Aguilar et al., 2007; Broers and Van der Grift, 2004; Stuart et al., 2007), to use of mass balance based on known loading of $\mathrm{N}$ at the surface (Lamontagne, 2002), to mass-transfer functions (Pinault and Dubus, 2008), to simple-one dimensional flow models of downward transport at individual sites (Young et al., 1976) or aggregated groundwater bodies as a whole (Visser et al., 2009a), to application of groundwater flow and transport models that include nonpoint source pollutants and macro-dispersivity(Kourakos et al., 2012; Orban et al., 2010). Böhlke and Denver (1995)used groundwater dating, supported by isotopic measurements of nitrate and dissolved gas analysis, to relate observed nitrate trends to historical nitrate application and denitrification. Groundwater dating has since been applied in many cases to aid trend detection and extrapolation (Burow et al., 2007; MacDonald et al., 2003; Wassenaar et al., 2006).Tesoriero et al. (2007) applied groundwater tracer-based ages and redox indicators in a series of wells along flow-paths in four settings to assess the fate and transport of nitrate and other nonpoint source pollutants and showed that increases in nitrate concentrations in groundwater are related to increases in fertilizer applications that took place after about 1960. Visser et al. (2007b)demonstrated that such upward trends in concentrations of nitrate and other related agricultural contaminants have been reversed by legislation limiting nitrate loadings at the national and European level.

Three factorscontrol trends in concentrations of diffuse contaminants at wells: 1) historical inputs, 2) travel times to the well, and 3) geochemical reactions along the groundwater flow path. One approach to projecting the trends in nitrate concentration in water supply wells is to combine statistical reconstructions of nitrate inputs with inferredtravel time distributions from recharge to the well. However, the travel time distribution from recharge to the well cannot be measured directly (Massoudieh and Ginn, 2011) and is often described using mathematical lumped parameter models (LPMs) prescribing its shape (Maloszewski and Zuber, 1993; Maloszewski and Zuber, 1998)fitted to measured concentrations of a number of tracers (Åkesson et al., 2014; Corcho Alvarado et al., 2007; Lehmann et al., 2003; Plummer et al., 2001; Solomon et al., 2010; Sültenfuß et al., 2011; Visser et al., 2013b). Recently, non-parametric groundwater age distributions have been derived from age tracers that, unlike the LPMs, have no prescribed shape(Liao et al., 2014; Massoudieh et al., 2014; McCallum et al., 2014; Visser et al., 2013a). 
Withthe LPM representing the travel time distribution from recharge zone to receiving wells and knowing the historical trend of nitrate concentrationsin recharginggroundwater and the overall rates of nitrate transformations, the future trend of nitrate in the wells can be projected. However, when using environmental tracers to infer the parameters of LPMs, there are multiple sources of uncertaintythat propagate into the projection of nitrate trends(Green et al., 2014). These uncertainties include those associated with measured tracers (due to both sampling and analytical methods), representativeness of the samples due to spatial and temporal heterogeneity, uncertaintydue to non-conservative tracer transport, making the apparent age of tracers different than the age of water, uncertaintyin tracer concentrations at the time of recharge, and most importantly, model structural error due to the fact that the appliedLPM is at best a simplification of the real residence time distribution. To obtain a reliable projection, these uncertainties need to be incorporated into the analysis.

For nitrate, the possibility of reactive transport (i.e.,denitrification) along the groundwater flow path needs to be ruled out or explicitlymodeled (Liao et al., 2012). While the effect of denitrification on groundwater nitrate flux has been found to be limited in some areas (Green et al., 2008a; Green et al., 2008b), estimating denitrification rates in groundwater bodies is complicated due to mixing along flow paths (Green et al., 2010) and at the well (Green et al., this issue). Dissolved $\mathrm{N}_{2}$ produced by denitrificationis a direct measure of saturated zone denitrification(Singleton et al., 2007; Vogel et al., 1981), while a shift in oxygen and nitrogen isotopes of nitrate is an indication of denitrification in both the unsaturated and saturated zone (Mariotti et al., 1988; McNab et al., 2007).

Bayesian inference has been demonstrated to be a powerful method to perform inverse uncertainty propagation for age distribution modeling (Massoudieh et al., 2012; Massoudieh et al., 2014).Instead of providing single valueestimates of the model parameters, Bayesian inference providesthe joint probability distributions of the estimated values for the parameters of the groundwater age distributions. Massoudieh et al. (2012)evaluated the appropriateness of several different LPM forms in reproducing the measured tracers using two different measures of goodness of fit including Bayes Factors and Deviance Information Criteria (DIF). Massoudieh et al. (2014)evaluated the information content of temporal measurement of tracers and compared it with single snapshots and showed that in certain cases, having multiple samples collected at large time intervals can provide additional confidence in the estimated LPMs. These studies applying Bayesian inference have relied only on age tracers to derive the age distribution. The Bayesian inference framework can be extended to include nitrate and to project an ensemble of future nitrate trends in drinking water production wells. Historical time series of measured nitrate concentrations can further be included in the Bayesian framework to support the groundwater age distribution. Bayesian inference reveals non-uniqueness and correlations between the parameters and provides an assessment of the information content of both the tracers and other sources of data that are included.

In this study, public supply wells from Turlock, CA, where nitrate concentrations are rising, were sampled for multiple age tracers. Multiple tracers were applied to characterize differently-aged groundwater components in an effort to constrain the age distribution to the extent possible using onetime observations. A number of age tracers are suitableat the time-scale relevant for well vulnerability and response (years to decades): ${ }^{85} \mathrm{Kr}$ (Althaus et al., 2009; Smethie et al., 1992), tritium-helium (Poreda 
et al., 1988; Schlosser et al., 1988), chlorofluorocarbons (Busenberg and Plummer, 1992), sulfurhexafluoride (Busenberg and Plummer, 2000), and ${ }^{39} \mathrm{Ar}$ (Loosli, 1983; Loosli et al., 1989; Oeschger et al., 1974). In addition, terrigenic helium(Marine, 1979)typically used for groundwater age dating in the range of $10^{3}$ to $10^{6}$ years, and ${ }^{14} \mathrm{C}$, limitedto dating groundwater up to approximately 40,000 years due to its 5,730 year half-life,can be used to distinguish the contribution of an old, pre-modern, nearly nitrate-free groundwater component diluting the modern fraction. For this study, a combination of ${ }^{85} \mathrm{Kr}$, ${ }^{3} \mathrm{H}$, tritiogenic ${ }^{3} \mathrm{He}$, terrigenic ${ }^{4} \mathrm{He}$ and $\delta^{13} \mathrm{C}$ and ${ }^{14} \mathrm{C}$ were applied. Age tracer results and nitrate concentration history at the wells are modeled in a Bayesian statistical framework in order to forecast future nitrate concentrations along with estimates of confidence intervals for the predictions at each well. Groundwater age distribution and nitrate concentrations were modeled based on tracer data, nitrate time series, and a combination of tracer data and nitrate time series. The results are discussed with respect to information content of the data sources and the ability to reliably project trends in future nitrate concentrations and the probability of future nitrate concentrations exceeding the USEPA $\mathrm{MCL}$ of $45 \mathrm{mg} / \mathrm{L}$ as nitrate This is the first study to include nitrate data as an objective of the age distribution and nitrate prediction model framework.Additional analyses (dissolved nitrogen, oxygen and noble gases, and isotopes of nitrogen and oxygen in nitrate) were conducted on all groundwater samples to investigate the potential for denitrification along the flow path.

\section{Methods}

\subsection{Site Description}

Turlock, California (population 68,000) is located in Stanislaus County, one of California's top ten agriculture counties and one of the top producers of agricultural commodities in the nation. Applied fertilizers are a likely factor contributing to high levels of nitrate contamination in the groundwater. Regional crops include grain, hay, truck and berry crops, fruits and nuts, with almonds covering over 65,000 hectares in Stanislaus County- by far the largest crop in size and revenue (Stanislaus County, 2012). Additionally, almonds are large users of $\mathrm{N}$ fertilizers and water, requiring approximately 308 kilograms of nitrogen fertilizer per hectare per year (California, 2012). The land use history in and near Turlock was examined in order to qualitatively assess the history of potential sources of nitrate to groundwater. The Turlock urban area has expanded significantly into formerly agricultural land over the past century (Figure 1). The input function of nitrate in groundwater beneath agricultural areas near Modesto (Stanislaus County) was used for modeling historical and future nitrate trends, (Figure 2), which was estimated from county level historical nitrogen fertilizer sales (Burow et al., 2008a)obtained from TracerLPM(Jurgens et al., 2012).Since actual fertilizer applications at the farm/field level are not reported, fertilizer sales offer a proxy for applications, as noted byBurow et al. (2008a). County level inputs of nitrogen to agricultural land (Alexander and Smith, 1990; Ruddy et al., 2006)correlate to nitrate concentrations in groundwater monitoring wells, when groundwater age is considered, in both the US (Böhlke and Denver, 1995; Böhlke et al., 2002)and in Europe (e.g.(Hansen et al., 2010; Visser et al., 2007a).

In 2012, over 5,600 hectare-meters of groundwater were used for urban purposes and 56,740 hectaremeters of groundwater and surface water were used for agriculture in the Turlock area. Groundwater accounts for all of Turlock's drinking water, and with average concentrations increasing from $12 \mathrm{mg} / \mathrm{L}$ to 
$21 \mathrm{mg} / \mathrm{L}$ in the last twenty years(Turlock Groundwater Basin Association, 2008), rising nitrate levels have become a major concern for the drinking water supply. Within the last ten years, two wells were closed due to nitrate levels exceeding the $\mathrm{MCL}$ of $45 \mathrm{mg} / \mathrm{L}$ (Turlock Groundwater Basin Association, 2008)and Well 32 was closed in July 2015 due to nitrate concentrations above the MCL.

The Turlock groundwater basin is a subbasin of the San Joaquin Valley Groundwater Basin comprising Cenozoic unconsolidated and consolidated sedimentary deposits.The Eocene lone Formation, the Lower-Miocene Valley Springs Formation, and the Miocene-Pliocene Mehrten Formation make up the consolidated deposits. The lone Formation is primarily made up of sandstone and clay(Arkley, 2009). Rhyolitic ash and clay are the main lithologies of the Valley Springs Formation. The Mehrten Formation is predominately composed of lithic sandstones, andesitic tuff and gravel. The Mehrten Formation is a significant aquifer that typically yields large amounts of water to wells. The unconsolidated deposits that overlie the Mehrten Formation are the late Pliocene to early Pleistocene Turlock Lake Formation, the Pleistocene Riverbank Formation and the late Pleistocene Modesto Formation. The main lithologies of these formations are granitic sands above stratified silt and sands. The Corcoran Clay is a major aquitard within the Turlock Formation. This aquitard is the uppermost portion of the Turlock Formation and is in contact with the Riverbank Formation, however, it is only found in the western section of the Turlock Subbasin. The Corcoran Clay separates the upper unconfined aquifer and the lower confined aquifer(Burow et al., 2008a).The upper unconfined aquifer is approximately $45 \mathrm{~m}$ thick and supplies the western part of the Subbasin with water for agriculture and private domestic wells. The deeper aquifer is semi-confined on the eastern side of the Subbasin. This aquifer provides a large amount of water for agriculture and municipal purposes. Wells that are deeper than $60 \mathrm{~m}$ are generally supplied by this aquifer. All wells except 4, 14 and 20 are screened entirely below $60 \mathrm{~m}$.Well 36 has a somewhat deeper top perforation and somewhat deeper bottom perforation than the other wells, and its chemical and isotopic signature differs significantly from the other wells, as described below.

\subsection{Sample Collection and Analysis}

Samples were collected between 30 June and 2 July 2014 from nine public drinking water supply wellsin the City of Turlock (Figure 1) and analyzed for multiple constituents at Lawrence Livermore National Laboratory. Perforated intervals of the sampled wells varied from $43 \mathrm{~m}$ to $174 \mathrm{~m}$ below the land surface (Table 1). Some wells have multiple perforations (not shown in Table 1). Major anion $\left(\mathrm{F}^{-}, \mathrm{Cl}^{-}, \mathrm{Br}^{-}, \mathrm{NO}_{3}{ }^{-}\right.$, $\mathrm{SO}_{4}{ }^{2-}$ ) samples (125 mL Nalgene bottles) were analyzed on an ion chromatograph (Metrohm model 881 Compact IC Pro). The analytical uncertainty for major anions is typically $10 \%$. Tritium samples (1L glass bottle) were analyzed by ${ }^{3} \mathrm{He}$ accumulation and noble gas mass spectrometry(Clarke et al., 1976; Surano et al., 1992). Noble gas samples (9.75 $\mathrm{cm}^{3}$ pinch-clamped copper tubes) were analyzed for dissolved concentrations of neon, krypton and xenon by a quadrupole mass spectrometer (SRS RGA200) using isotope dilution ( ${ }^{22} \mathrm{Ne},{ }^{86} \mathrm{Kr}$ and ${ }^{136} \mathrm{Xe}$ ), argon by high capacitance manometer, and helium isotopes by a static sector field mass spectrometer (VG5400) (Visser et al., 2013d). Noble gas recharge temperature, tritiogenic ${ }^{3} \mathrm{He}$ and terrigenic ${ }^{4} \mathrm{He}$ components were derived assuming unfractionated excess air (Moore et al., 2006; Visser et al., 2014b).The uncertainty in the derived parameters was calculated by propagating the analytical uncertainty(Visser et al., 2014a). Dissolved gas samples (40 mL amber VOA vials) were analyzed for $\mathrm{N}_{2}, \mathrm{O}_{2}$ and Ar using a Membrane Inlet Mass Spectrometer (Kana et al., 1994; 
$c_{i}(\mathbf{x}, t)=\int_{-\infty}^{t}\left[c_{i, o}\left(\tau-t_{v z d, i}\right)+\lambda_{i}^{\prime} \tau\right] \rho_{i}(\mathbf{x}, t, t-\tau) d \tau+f_{i, m} c_{i, d}$

$c_{i}(\mathbf{x}, t)=\int_{-\infty}^{t} m_{i} c_{j, o}\left(\tau-t_{v z d, i}\right) e^{-\lambda_{j} t_{v d, j}}\left[1-\mathrm{e}^{-\lambda_{j}(t-\tau)}\right] \rho_{i}(\mathbf{x}, t, t-\tau) d \tau$ scintillation counting procedure are provided in the Supplementary Information.

[TABLE 1]

\subsection{Bayesian inference of age distribution} decay another tracer, can be respectively expressed as:

$c_{i}(\mathbf{x}, t)=\left(1-f_{i, m}\right) \int_{-\infty}^{t} m_{i} c_{i, o}\left(\tau-t_{v z d, i}\right) \rho_{i}(\mathbf{x}, t, t-\tau) \mathrm{e}^{-\lambda_{i}\left(t-\tau+t_{v d, i}\right)} d \tau+f_{i, m} c_{i, d}$

Singleton et al., 2007). Water stable isotope $\left(\delta^{2} \mathrm{H}\right.$ and $\delta^{18} \mathrm{O}$ ) samples ( $30 \mathrm{~mL}$ glass bottle) were analyzed using a Los Gatos Research DLT-11 liquid water laser isotope analyzer. Carbon-14 samples (250 mL amber glass bottles) were analyzed by accelerator mass spectrometry and reported as percent modern carbon relative to a NIST oxalic acid standard. Dissolved inorganic carbon and $\delta^{13} \mathrm{C}$ samples $(40 \mathrm{~mL}$ amber VOA vials) were analyzed usingthe automated DIC-dissolved organic carbon-isotope ratiomass spectrometry technique (St-Jean, 2003) consisting of anOI Analytical Model 1030 Carbon analyzer and a Micromass(now Isoprime Ltd) IsoPrime isotope ratio mass spectrometer.Carbon isotope compositions $\left({ }^{13} \mathrm{C} /{ }^{12} \mathrm{C}\right)$ are reported as deltavalues in per mil relative to the Vienna Peedee Belemnitereference, with an analytical uncertainty of $\pm 0.3 \%$ (Singleton and Moran, 2010). Samples for ${ }^{85} \mathrm{Kr}$ analysis were collected at six wells using a field portable Gas Extraction System (GES) (Moran et al., 2008). Dissolved gases were extracted from large volumes of water (2100-4300 L) using membrane contactors. The extracted gas samples (57-82 L-STP) were compressed into $20 \mathrm{~L}$ air cylinders, and contained $0.16-0.33 \mathrm{~cm}^{3} \mathrm{STP} \mathrm{Kr}$, assuming a $100 \%$ gas extraction efficiency.Sample collection took 1 to 4 hours. Krypton was purified at Lawrence Livermore National Laboratory using a combination of molecular sieve and activated charcoal traps, and transferred to a liquid scintillation vial. The ${ }^{85} \mathrm{Kr}$ activity was measured by liquid scintillation on a Quantulus 1220 liquid scintillation counter from PerkinElmer. A subsample of the purified Kr was analyzed at Bern Universityby low level gas proportional counting. Details of the purification and liquid

The method of stochastic inference of age distribution using environmental tracer data and historic nitrate concentration is mainly based onMassoudieh et al. (2012). The general equation for predicting concentrations of each tracer given a groundwater age distribution fortracers with first order decay such as ${ }^{85} \mathrm{Kr},{ }^{39} \mathrm{Ar},{ }^{14} \mathrm{C},{ }^{3} \mathrm{H}$, tracers with linear accumulation such as ${ }^{4} \mathrm{He}$, and tracers produced as a result of 
where $\mathbf{x}$ and $t$ are the location and time of sample respectively, $m_{i}$ is a source multiplier representing mainly the transformations affecting tracer $i$, at recharge; for example biotransformation or plant uptake of nitrate, $c_{i, o}$ is the concentration in the recharge or precipitation, $t_{v z d, i}$ is the travel time in the vadose zone for tracers that will undergo decay in the vadose zone such as ${ }^{3} \mathrm{H}, \rho_{i}(\mathbf{x}, t, t-\tau)$ is the tracer age distribution (not necessarily the same as water age distribution), $\lambda_{i}$ is the decay rate for tracers undergoing first order decay, $f_{i, m}$ is the fraction of a tracer contributed from mineral dissolution, $c_{i, d}$ is the concentration of tracer $i$ in the mineral solution, and $\lambda_{i}^{\prime}$ is the linear accumulation rate for tracers undergoing linear accumulation. For conservative non-reactive tracers, $\rho_{i}(\mathbf{x}, t, a)$ is the same as the water age distribution, however for tracers undergoing mass exchange with the soil matrix, the tracer age distribution can be obtained from the water age distribution as:

$\rho_{i}(X, t, a)=\left(1-f_{i, m}\right) \frac{1}{R_{i}} \rho_{m}\left(\mathbf{X}, t, \frac{a}{R_{i}}\right)$

where $f_{i, m}$ is the fraction of a tracer contributed from mineral dissolution, $\rho_{m}(X, t, a)$ is the mobile phase (or groundwater age), $R_{i}$ is the retardation factor, and $\rho_{i, d}$ is the age distribution of tracers contributed by mineral dissolution. In the case of most linearly decaying tracers, $\rho_{i, d}$ can be assumed to be sufficiently large so that the tracers contributed by mineral dissolution can be assumed to be negligible and therefore the mineral dissolution acts as a dilution factor for the tracer signature to which it is contributing.

It should be noted that Eq. (1) can be used to consider $\delta^{13} \mathrm{C}$, used for indicating the contribution of mineral dissolution, by setting $\lambda_{i}=0, c_{i, o}(t)={ }^{13} C_{\text {bio }}$ (biogenic ${ }^{13} \mathrm{C} /{ }^{12} \mathrm{C}$ isotope ratio), $c_{i, d}={ }^{13} C_{\min }$ (mineral ${ }^{13} \mathrm{C} /{ }^{12} \mathrm{C}$ isotope ratio), and $m_{i}=1$.

The groundwater age at the time and location of each sample is typically expressed as a Lumped Parameter Model (LPM) composed of one or a combination of several mathematical distributions (Maloszewski and Zuber, 1982). Onegoal of using multiple tracers is to estimate the parameters defining LPMs as well as other parameters affecting the tracer concentrations. The posterior distribution of a parameter can be expressed based on Bayes theorem as:

$$
\pi(\boldsymbol{\Phi}, \boldsymbol{\Gamma} \mid \tilde{\mathbf{C}}) \propto \pi(\tilde{\mathbf{C}} \mid \boldsymbol{\Phi}, \boldsymbol{\Gamma}) \pi(\boldsymbol{\Phi}, \boldsymbol{\Gamma})
$$

where $\boldsymbol{\Phi}$ is the vector of all model unknown parameters including parameters of the LPM model and physical and chemical parameters affecting tracer concentrations, $\boldsymbol{\Gamma}$ is the variance-covariance matrix of observation error, $\tilde{\mathbf{C}}$ contains the observed concentration of all tracers, $\pi(\boldsymbol{\Phi}, \boldsymbol{\Gamma} \mid \tilde{\mathbf{C}})$ is the posterior joint probability distribution of the parameters and elements of variance-covariance matrix given the 
observed concentrations, $\pi(\tilde{\mathbf{C}} \mid \boldsymbol{\Phi}, \Gamma)$ is the likelihood of observed tracer concentrations given the

parameters $\boldsymbol{\Phi}$, and variance-covariance matrix $\boldsymbol{\Gamma}$, and $\pi(\boldsymbol{\Phi}, \boldsymbol{\Gamma})$ is the prior distribution of model parameters and variance-covariance matrix. If it is assumed that the observation errors structure of each tracer is the same and that the errors associated with each data point (sample/tracer) are independent (Massoudieh et al., 2014), then the likelihood function can be written as:

263

$$
\pi(\tilde{\mathbf{C}} \mid \boldsymbol{\Phi}, \boldsymbol{\Gamma}) \propto \frac{\prod_{i=1}^{m} \Pi_{j=1}^{n} \Pi_{k=1}^{l_{i j}} g^{\prime}\left(\tilde{c}_{i j k}\right)}{\prod_{i=1}^{m} \sigma_{i}^{\sum_{j=1}^{n} l_{i j}} \sum_{j=1}^{n} \sum_{k=1}^{l_{i j}} \frac{\left[g\left(c_{i j k}\right)-g\left(\tilde{c}_{i j k}\right)\right]^{2}}{2 \sigma_{i}^{2}}}
$$

where $m$ is the number of tracers used in the study, $n$ is the number of sampling locations (or wells in this case), and $l_{i j}$ is the number of samples of tracer $i$ in well $j ; \tilde{c}_{i j k}$ and $c_{i j k}$ are respectively the measured and modeled concentration or isotope ratio of tracer $i$ in well $j$ and in the $k^{\text {th }}$ sample (or sampling time), $\sigma_{i}$ is the observed error standard deviation of tracer $i$, and $g$ is a transformation function determining the error structure. For example a $g(x)=x$ results in a normally distributed error structure while $g(x)=\ln (x)$ means an assumption of a log-normally distributed error. It should be noted that the method allows some of the parameters to be applied collectively to all sampling locations while some of the parameters described in Eq. (1) can be considered to have different values for each well.

The prior distributions were presumed to be log-normally distributed for all parameters with the exception of $\delta^{13} C_{\min }$ and $\delta{ }^{13} C_{\text {bio }}$ which were considered to be normally distributed. The spread of the prior distributions for all parameters were considered large enough so that it covers all likely values. $\delta$ ${ }^{13} \mathrm{C}_{\min }$ and $\delta{ }^{13} \mathrm{C}_{\text {bio }}$ values are known with relatively good confidence and therefore their prior distributions were considered normal distributions with means of respectively $-25 \%_{0}$ and $1 \%$ respectively(Fontes and Garnier, 1979), with standard deviations of $2 \%_{0}$ and $0.5 \%$. The MetropolisHasting(Metropolis et al., 1953)MCMC algorithm was used to generate 500,000 samples from the posterior distribution of the parameters. 200,000 of the initial samples were discarded as a"burn-in" period. The method of moments suggested by Geweke (1992)and Geweke and Tanizaki (2001)was used to evaluate the convergence of the MCMC algorithm.

\subsection{Age Models, Scenarios and Analysis of Results}

A binary mixture of an Inverse Gaussian model and a Dirac model was used to represent the age distribution. An Inverse-Gaussian model represented the young fraction and a Dirac (piston flow) model represented the old fraction of the sampled groundwater at each well. The Dirac model for the old fraction is likely not an accurate representation, but accurate tracers covering the $100-10,000$ year age range are lacking. Also, since nitrate is near zero in pre-modern groundwater, the age distribution of the old fraction is not as important in determining the projected nitrate concentration as the magnitude of the old fraction. Preliminary tests showed that other combinations of travel time distribution models 
(including exponential, partial exponential) were not able to reproduce the tracer data. Age distribution model parameters and unknown physical parameters (terrigenic helium release, dissolved inorganic carbon contribution from carbonate dissolution) were estimated using a Bayesian inference, resulting in the posterior probability distribution - including the associated uncertainty - of the parameters and projected nitrate concentrations.

To evaluate the comparative ability of age tracers and nitrate time-series to inform about future trends in nitrate level in wells, three scenarios were evaluated to study the ability of the Bayesian inference framework to reproduce measured tracer concentrations and nitrate, estimate groundwater age distributions and predict nitrate concentrations: Scenario 1 includes both tracer and nitrate data, Scenario 2 includes nitrate data only, and Scenario 3 includes tracer data only. Under Scenario 1, four parameters were estimated that apply to all wells: the ${ }^{13} \mathrm{C}$ isotope end members of mineral carbonate source and biological influenced soil carbon dioxide $\left({ }^{13} \mathrm{C}_{\min }\right.$ and $\left.{ }^{13} \mathrm{C}_{\mathrm{bio}}\right)$, the terrigenic helium accumulation rate and the nitrate multiplier. The nitrate multiplier is a number to scale the input concentrations to the observed concentrations. While the reconstructed nitrate input is expected to capture the dynamic of increased nitrate concentrations in first encounter groundwater, the nitrate multiplier allows for adjustments to the absolute concentration of nitrate entering groundwater. Five parameters are estimated for each well: the fraction of mineral carbon $\left(f_{\min }\right)$, the fraction of old groundwater $\left(f_{\text {old }}\right)$, the mean age of the old groundwater component $\left(\mu_{\tau, \text { old }}\right)$, and the mean $\left(\mu_{\tau, \text { young }}\right)$ and standard deviation ( $\sigma_{\tau, \text { young }}$ ) of the Inverse Gaussian age distribution describing the young groundwater component. In addition, the standard deviation of model uncertainty is estimated for each tracer and for nitrate measurements, as part of the maximum likelihood estimation. The total number of parameters for Scenario 1 is 51 . Scenario 1 is constrained by 45 tracer measurements and over 400 nitratemeasurements. Under Scenario 2, the nitrate multiplier is the only common parameter, because the nitrate data do not contain information about the age of the old component or carbon isotope systematics. The Inverse Gaussian age distribution of the young component is constrained by the same two parameters $\left(\mu_{\tau, \text { young }}\right.$ and $\left.\sigma_{\tau, y o u n g}\right)$ and the old fraction $\left(f_{\text {old }}\right)$. The other parameters did not affect the nitrate prediction and were fixed to the values estimated by Scenario 3 to evaluate the ability of nitrate only data to capture age tracer data after parameter estimation. The total number of parameters for Scenario 3 is 26, constrained by over 400 nitrate measurements. Under Scenario 3, all common parameters (except the nitrate multiplier), well specific parameters and tracer model uncertainty parameters were estimated. The total number of parameters was 49 , constrained by 45 measured tracer concentrations, although it should be noted that narrow prior distributions were considered for some of the parameters such as ${ }^{3} \mathrm{C}_{\mathrm{min}}$ and ${ }^{13} \mathrm{C}_{\text {bio. }}$. In this scenario, the nitrate multiplier was estimated separately after the age distributions were estimated by Bayesian inference, by minimizing the mean residual between the measured and modeled nitrate concentrations.

[TABLE 2]

Results are discussed in terms of the ability of the model to reproduce the measured tracer concentrations and nitrate time series, quantified by a simple ensemble regression $R^{2}$. The value of $R^{2}$ is calculated based on the ensemble of model predictions which are based on the posterior distribution of 
the parameters. The ability to predict future nitrate trends was evaluated by the confidenceby which nitrate concentrations in the year 2040 were predicted as determined by the spread of projections.

\section{Results}

\subsection{Tracer signatures}

Eight of the nine sampled wells show a similar signature in terms of general chemistry, nitrate (Table 3 ) and tracer concentrations (Tables $5,6,7,8$ ), while Well 36 is distinctly different. The eight wells produce water containing both nitrate and tritium, indicating a component of modern groundwater with anthropogenic impacts. All eight wells also show signs of pre-modern fossil water, containing terrigenic helium (Table 7) and measured ${ }^{14} \mathrm{C}$ activities below modern (Table 8 ). The results from these wells are described in more detail below. Well 36 is distinctly and significantly different from the other wells in nearly every aspect, despite the fact that the total well depth is only $26 \mathrm{~m}$ deeper thanthat of nearbywell 35 (Table 1). The tritium concentration (Table 7) was below the detection limit $(0.4 \mathrm{pCi} / \mathrm{L})$ indicating a modern component of groundwater is not present. The electrical conductivity was higher $(0.70 \mathrm{mS} / \mathrm{cm}$, Table S1) largely due to higher concentrations of chloride (160 mg/L) and sodium (74 $\mathrm{mg} / \mathrm{L})$, despite lower concentrations of nitrate $(1.1 \mathrm{mg} / \mathrm{L})$ and sulfate $(1.8 \mathrm{mg} / \mathrm{L})$ (Table 3$)$. The noble gas recharge temperature was $3.0 \pm 1.2{ }^{\circ} \mathrm{C}$ lower than other samples, while the discharge temperature was $2.4 \pm 0.4{ }^{\circ} \mathrm{C}$ higher (Table 6). The difference between recharge and discharge temperature caused by geothermal warming was $9.2 \pm 1.0^{\circ} \mathrm{C}$. The well 36 sample contained a large component of terrigenic helium $\left(4.0 \pm 0.08 \times 10^{-6} \mathrm{~cm}^{3} \mathrm{STP} / \mathrm{g}\right)$ with a helium isotope ratio of $6.2 \pm 0.3 \times 10^{-7}$, corresponding to a mantle contribution of $5 \%$ (Table 7 ). The terrigenic helium isotope ratio, with associated uncertainty, was used to calculate the tritiogenic helium-3 component in all other samples. Analysis of dissolved $\mathrm{N}_{2}$ and $\operatorname{Ar}$ (Table 4) showed an excess nitrogen concentration of $3.5 \pm 0.7 \times 10^{-3} \mathrm{~cm}^{3} \mathrm{STP} / \mathrm{g}$. This would correspond to the denitrification of $19 \mathrm{mg} / \mathrm{L} \mathrm{NO}_{3}$, but the excess nitrogen in Well 36 is most likely derived from mantle fluids. Jenden et al. (1988) report a $\mathrm{N}_{2} /{ }^{4} \mathrm{He}$ ratio of 2000 and a ${ }^{3} \mathrm{He} /{ }^{4} \mathrm{He}$ ratio of 4.1 $\times 10^{-6}$ in nitrogen-rich natural gases beneath the Central Valley.Considering the $4.0 \times 10^{-6} \mathrm{~cm}^{3} \mathrm{STP} / \mathrm{g}$ terrigenic ${ }^{4} \mathrm{He}$ and $2.5 \times 10^{-12} \mathrm{~cm}^{3} \mathrm{STP} / \mathrm{g}$ terrigenic ${ }^{3} \mathrm{He}$, estimates of the mantle component of $\mathrm{N}_{2}$ vary between $1.2 \times 10^{-3}$ and $8.0 \times 10^{-3} \mathrm{~cm}^{3} \mathrm{STP} / \mathrm{g}$, explaining most, if not all of the observed excess nitrogen. While the dissolved inorganic carbon (DIC) concentration was similar to other samples, the $\delta^{13} \mathrm{C}(-$ $28.6 \pm 0.1 \%$ ) was $14 \pm 0.2 \%$ o lower and the ${ }^{14} \mathrm{C}$ value was only 5 percent modern carbon (pmC). Due to the low $\delta^{13} \mathrm{C}$ and the potential for a mantle component of $\mathrm{CO}_{2}$ (Kulongoski et al., 2013), ${ }^{14} \mathrm{C}$ cannot be used to calculate the age of this water. Because no modern groundwater was detected in Well 36 , it was excluded from the Bayesian inference modeling. It appears that well 36 captures groundwater from the underlying deep, saline aquifer, with much longer flow paths, but the reason for its distinct capture zonewas beyond the scope of this study.

\subsection{Nitrate concentrations, isotopes and dissolved $\mathrm{N}_{2}$}

Nitrate concentrations range from 15 to $38 \mathrm{mg} / \mathrm{L}$ as $\mathrm{NO}_{3}($ Table 3$)$ and the concentrations measured at LLNL agree closely with recent values from the California Department of Public Health database (www.geotracker.ca.gov). Historical time seriesshow increasing nitrate concentrations in wells 4, 8, 14, 
water supply, as noted above. The median and $95 \%$ percentile of nitrate concentrationsin pre-modern oxic or sub-oxic groundwater samples collected in the Central Valley are $3 \mathrm{mg} / \mathrm{L}$ and $12.7 \mathrm{mg} / \mathrm{L}$ respectively(Visser et al., 2013c) and the criterion often used for identifying anthropogenic nitrate is $>13$ $\mathrm{mg} / \mathrm{L}$ (Squillace et al., 2002). Natural, background nitrate concentrations are therefore likely $<13 \mathrm{mg} / \mathrm{L}$ and increases in nitrate observed in wells over the last few decades can therefore be attributed to anthropogenic sources.

Compared to the nitrate input, increases in nitrate concentrations are delayed by 40 to 50 years. Although the start of the upward trends are not always captured, the trend slopes compared to the concentration levels indicate a sudden, rather than gradual, increase in nitrate concentrations, pointing towards a groundwater age distribution with a limited spread, resembling piston flow, with a sudden increase in the recharge nitrate concentration rather than the expected gradual increase for an exponential model. The sudden increase in nitrate concentrations could also be explained by transience in the flow pattern which is not captured by steady-state LPM models(Massoudieh et al., 2012). Nitrate linear regression trend slopes in seven of the eight wells with modern groundwater vary between 0.56 and $1.7 \mathrm{mg} / \mathrm{L}$ per year, with $\mathrm{R}^{2}$ values between 0.69 and 0.94 . The trend slope in Well 29 is decreasing, at $0.29 \mathrm{mg} / \mathrm{L}$ per year with an $\mathrm{R}^{2}$ of 0.1 . The trend slopes are all lower than the initial slope of the nitrate input $(2.3 \mathrm{mg} / \mathrm{L} /$ year).This is consistent with mixing or varying levels of dilution with pre-modern groundwater, but can also be the result of hydrodynamic dispersion in the aquifer. If these linear trend slopes were to persist, nitrate concentrations would exceed the MCL of $45 \mathrm{mg} / \mathrm{L}$ in 2040 for five of the sampled wells. In three of these wells, the entire $95 \%$ confidence interval exceeds the MCL (figure 7).

The likely sources of nitrate are identified by examination of the stable isotopes of nitrate (Table 4). Figure 3 shows the $\delta^{15} \mathrm{~N}-\mathrm{NO}_{3}$ and $\delta^{18} \mathrm{O}-\mathrm{NO}_{3}$ isotope fields for different possible sources of nitrate (Kendall, 1998). The $\delta^{18} \mathrm{O}-\mathrm{NO}_{3}$ of $\mathrm{N}$ sources that undergo nitrification ('manure and septic', 'soil $\mathrm{N}^{\prime}$, and ' $\mathrm{NH}_{4}$ in fertilizer') have been adjusted based on observed $\delta^{18} \mathrm{O}-\mathrm{H}_{2} \mathrm{O}$ values and the assumption thatoxygen in nitrate is derived from water and atmospheric oxygen at a 2:1 ratio during nitrification (Hollocher, 1984; Yoshinari and Wahlen, 1985). Nitrate in wells from Turlock falls in a relatively narrow range, between $+4.6 \%$ and $+8.4 \%$ o for $\delta^{15} \mathrm{~N}-\mathrm{NO}_{3}$, and between $-0.1 \%$ ond $+1.9 \%$ o for $\delta^{18} \mathrm{O}-\mathrm{NO}_{3}$ (except Well 36 which has a $\delta^{18} \mathrm{O}-\mathrm{NO}_{3}$ value of $+5.2 \%$ ). Most of these values fall in a range of overlap that includes ammonium fertilizer, soil $\mathrm{N}$ and animal waste sources.

Measured nitrate isotopes show a trend with a slope of approximately $0.5\left(R^{2}=0.54\right)$, suggesting that the nitrate isotopes have been altered by denitrificationto some extent and that the original source signature is at the low end of the range for $\delta^{15} \mathrm{~N}-\mathrm{NO}_{3}$ and $\delta^{18} \mathrm{O}-\mathrm{NO}_{3}$. The isotope signatures are then consistent with a $\mathrm{NH}_{4}$ fertilizer source, which is likely, considering the land use history in the Turlock area and the requirements for inorganic $\mathrm{N}$ fertilizers for the main crops (originally, mainly alfalfa and more recently, almonds). The denitrificationthat leads to the observed trend in the isotope signature probably takes place in the vadose and not in the saturated zone, considering measurements of dissolved excess nitrogen, the end product of denitrification.

Excess $\mathrm{N}_{2}$ from denitrification was calculated from the measured dissolved $\mathrm{N}_{2}$ and $A r$ concentrations assuming unfractionated excess air in addition to recharge concentrations in equilibrium with the 
atmosphere at $100 \mathrm{~m}$ elevation and $17.5^{\circ} \mathrm{C}$ (Table 4). Excess nitrogen was not detected in the eight modern wells above the equivalent of $7 \mathrm{mg} / \mathrm{L}$ of nitrate denitrified to $\mathrm{N}_{2}$ (95\% one-sided confidence interval). So, while nitrate isotopes show indications of denitrification, the absence of significant excess $\mathrm{N}_{2}$ indicates that denitrification in the saturated zone is not significant. Further, dissolved oxygen concentrations greater than $2 \mathrm{mg} / \mathrm{L}$ and low organic carbon concentrations suggest that the conditions necessary for saturated zone denitrification may not be present. A previous study (Burow et al., 2008a) applied a decay rate of $0.001 \mathrm{mg} / \mathrm{L}$ per year (as N) to account for denitrification in Modesto groundwater, based on previous estimates varying between 0 and $0.02 \mathrm{mg} / \mathrm{L}$ per year (as N)(McMahon and Chapelle, 2008). Therefore, we used the historical reconstruction of nitrate loading(Burow et al., 2008a) to predict future nitrate concentrations without explicitly considering denitrification.

\subsection{Age Tracers}

Tritium was detected in eight of the samples (Table 7), with concentrations between $2.0 \pm 0.35$ and $6.1 \pm 0.48 \mathrm{pCi} / \mathrm{L}$, indicating a component of modern groundwater. Compared to present day concentrations in the Tuolumne River $(10.2 \mathrm{pCi} / \mathrm{L})$, which is the presumed main source of recharge in this area, groundwater samples must have a significant age (1-2 half-lives) or be a mixture with pre-modern groundwater. Tritiogenic helium concentrations vary between the equivalent of $6.6 \pm 9.3 \mathrm{pCi} / \mathrm{L}$ and $58 \pm 11$ $\mathrm{pCi} / \mathrm{L}$ decayed tritium. The large uncertainty is the result of the correction for the terrigenic helium component. ${ }^{3} \mathrm{H} /{ }^{3} \mathrm{He}$ apparent ages, representing the initial tritium weighted mean of the modern component, vary between $23 \pm 18$ years and $57 \pm 5.7$ years. The initial tritium concentrations, calculated as the sum of tritium and tritiogenic helium concentrations, are well below the reconstructed concentrations of tritium in historical precipitation in California, as a result of mixing between modern and pre-modern groundwater.

Six wells were analyzed for ${ }^{85} \mathrm{Kr}$ (Table 5). ${ }^{85} \mathrm{Kr}$ was not detected at LLNL above the detection limit of 7$14 \%$ of the present day activity in air, which corresponds to the decay-corrected ${ }^{85} \mathrm{Kr}$ activity in air between 1982 and 1989. Sampled water must have recharged entirely before the 1980s, or at most, $14 \%$ of the produced water recharged the aquifer recently. Analysis of subsamples of purified krypton at the University of Bern resulted in ${ }^{85} \mathrm{Kr}$ detections of $1.6 \pm 1.3$ to $6.6 \pm 1.3 \mathrm{dpm} / \mathrm{cm}^{3} \mathrm{Kr}$, equivalent to $2 \%$ to $9 \%$ of the present day activity in air, which corresponds to the decay-corrected ${ }^{85} \mathrm{Kr}$ activity in air between 1968 and 1984 . The detection of ${ }^{85} \mathrm{Kr}$ in these samples is evidence of a fraction of water that recharged after the peak concentrations of tritium in precipitation and provides an additional constraint on the groundwater distribution and the projected response time for changes in nitrate loading to be observed at the wells.

Terrigenic helium concentrations (Table 7) vary between $56 \pm 3$ and $403 \pm 9 \times 10^{-9} \mathrm{~cm}^{3} \mathrm{STP} / \mathrm{g}$. Because the terrigenic helium isotope ratio $\left(6.2 \pm 0.3 \times 10^{-7}\right)$ indicates a small $(\sim 5 \%)$ mantle component, the source of the terrigenic helium is not solely in situ uranium and thorium decay, and groundwater ages cannot be attributed to these concentrations directly. Terrigenic helium correlates poorly $\left(R^{2}=0.25\right)$ with radiocarbon measurements, pointing to poorly defined source functions for ${ }^{14} \mathrm{C}$ and terrigenic helium and/or complex mixing patterns of groundwater ages rather than linear helium accumulation along groundwater flow paths (Plummer et al., 2012). 
Measured $\delta^{13} \mathrm{C}$ values (Table 8 ) are $-14.73 \%$ on average ( $\sigma=0.23 \%$ ). The mean and limited spread of $\delta^{13} \mathrm{C}$ values indicate that $\mathrm{DIC}$ in the aquifer is derived in approximatelyequal parts from soil gas $\mathrm{CO}_{2}$ and mineral carbonate dissolution, suggesting that dissolved inorganic carbon is in equilibrium with the aquifer materials, which is corroborated by groundwater $\mathrm{pH}$ values between 7.63 and 7.96 for eight of the wells. Correcting the measured ${ }^{14} \mathrm{C}$ values for carbonate dissolution using the measured $\delta^{13} \mathrm{C}$ ratios following the Pearson model(Fontes and Garnier, 1979),results in values between 52 and $130 \mathrm{pmC}$. A complex mixture of modern groundwater bearing ${ }^{14} \mathrm{C}$ from nuclear testing and fossil groundwater causes ${ }^{14} \mathrm{C}$ values to vary above and below modern, and contributes to the poor correlation with 455 terrigenic helium.

\subsection{Bayesian inference of residence time distributions and nitrate trends}

458 [FIGURE4]

459

460

461

462

463

\section{Tracer concentrations}

Scenario 3 (tracer concentrations only) is able to reproduce the measured tracer concentrations well (Figure4). The $95 \%$ credible interval (Cl) of modeled tracer concentrations encompasses the observed concentrations for all tracers with the exception of two $3 \mathrm{He}$ measurements. Measured concentrations are close to or within the center 50th percentile (dark orange shaded area) for ${ }^{3} \mathrm{H},{ }^{13} \mathrm{C},{ }^{4} \mathrm{He}$ and ${ }^{85} \mathrm{Kr}$. The variance of tracer concentrations is explained well for ${ }^{3} \mathrm{H},{ }^{14} \mathrm{C}$ and ${ }^{4} \mathrm{He}$ (ensemble $\mathrm{R}^{2}=0.63-0.73$ ), and to a lesser extent for ${ }^{3} \mathrm{He}$ (ensemble $\mathrm{R}^{2}=0.36$ ) (Table 9). The variance of $\delta^{13} \mathrm{C}$ measurements is very small, causing a poor explained variance (ensemble $R^{2}=0.11$ ). It should be noted that the ${ }^{85} \mathrm{Kr}$ measurements are explained best $\left(R^{2}=0.89\right)$. The ability of the model to reproduce measured concentrations is reflected in the estimated tracer uncertainty. Estimated model uncertainty for ${ }^{85} \mathrm{Kr}$ is less than the reported analytical uncertainty, suggesting that the Bayesian inference scheme assigns too much weight to these measurements. For other tracers, the model uncertainty is close to the measurement uncertainty $\left({ }^{13} \mathrm{C}\right)$ or within a factor of 2-3 $\left({ }^{3} \mathrm{H}\right.$ and $\left.{ }^{3} \mathrm{He}\right)$, suggesting that the error of the conceptual model is larger but of the same order of magnitude as the measurement uncertainty. For ${ }^{4} \mathrm{He}$ and ${ }^{14} \mathrm{C}$, the model uncertainty is much larger than the measurement uncertainty (error bars are smaller than symbols) suggesting that the conceptual model does not adequately represent reality. In scenario 3, the nitrate multiplier cannot be estimated directly using the Bayesian approach and thus it was estimated deterministically by minimizing the ensemble difference between measured and modeled nitrate data after obtaining the residence time distribution parameters using tracer data. A single value of $\mathrm{xx}$ was estimated for all wells.

Including nitrate as an objective for the age distribution model reduces the importance of the tracers as a model objective dramatically, as there are nearly ten times more nitrate measurements than tracer measurements available. Consequently, the credible intervals of the modeled tracer concentrations increase and larger discrepancies between model and measured values are accepted. The variance of measured tracer concentrations is poorly explained $\left(R^{2}<0.1\right)$, except for ${ }^{3} H\left(R^{2}=0.64\right)$. Modeled age distributions estimated by Scenario 2 (nitrate time-series alone) do not yield credible tracer concentrations, although ensemble $\mathrm{R}^{2}$ values are unexpectedly high for ${ }^{14} \mathrm{C}(0.54)$ and ${ }^{4} \mathrm{He}(0.50)$. 


\section{Common parameters}

489 The estimated $\delta^{13} \mathrm{C}$ signatures did not differ substantially from the mean values of prior distributions $490 \quad(1 \%$ and $-25 \%)$ showing there was no information in the tracer data that contradicted initial estimates or that the prior ranges are narrow enough to constrain the values. The credible interval of the radiogenic helium accumulation rate in Scenario 1 is from 0 to $0.04 \times 10^{-9} \mathrm{~cm}^{3} \mathrm{STP} / \mathrm{g} / \mathrm{year}$, less thanthat estimated by Scenario $3\left(0.04-0.08 \times 10^{-9} \mathrm{~cm}^{3} \mathrm{STP} / \mathrm{g} / \mathrm{year}\right)$. Assuming a porosity of 0.25 , the accumulation rate per $\mathrm{m}^{3}$ sediment $\left(10 \mu \mathrm{cm}^{3} \mathrm{STP} / \mathrm{m}^{3} /\right.$ year) lays one order of magnitude above the production rate by natural uranium and thorium decay. Combined with the helium isotope signature, this is evidence that helium migrates upward from the crust into the aquifers. The concentration of terrigenic(mainly radiogenic) helium is controlled by the ${ }^{4} \mathrm{He}$ accumulation rate, and two well specific parameters -the fraction of old groundwater and the crustal residence timeof the old groundwater component. Both parameters also influence the modeled ${ }^{14} \mathrm{C}$, further constraining the old fraction and age (though ${ }^{14} \mathrm{C}$ activity is also affected by reactions with inorganic carbon), while the old fraction also influences the young groundwater tracers. Overall, the old fraction is estimated to be larger in Scenario 3, and the credible interval is often wider than \pm 0.15 around the median estimate. This suggests that the old groundwater component is described with too many parameters, or constrained by too few tracers. The additional information from the nitrate time series reduces the credible interval of the old fraction to 0.2 in Scenario 1.

506

507

508

509

510

511

512

513

514

515

516

517

518

519

520

521

522

523

The nitrate multiplier parameter was estimated to be between 1.27 and 1.46 under Scenario 1, with both tracers and nitrate data as the objective. While a single multiplier does not capture the spatial and temporal variability of nitrate loading to first encounter groundwater, mixing of water with variable nitrate concentrations along flow paths and in the wells appears to even out systematic differences between the wells. The nitrate multiplier indicates that the nitrate prognosis at the groundwater basin scale is valid and accurate within $50 \%$. Scenario 2 (nitrate data only) predicts a smaller nitrate multiplier (0.8-1.1), mostly compensated by a larger fraction of old groundwater. In Scenario3, the nitrate multiplier estimated after Bayesian inference of the age distribution was 0.7.The residence time distributions obtained from scenario 3 where only tracers are used to determine the travel time distributions are unable to capture the general historic trends of nitrate concentrations in the wells. Also the age distributions obtained in scenario 3 are substantially different than those found in scenarios 1 and 2. This can be partly due to the fact that tracers alone do not adequately constrain residence time distributions and partly due to some level of inconsistency between the lag times present in the nitrate data and some of the tracers (mainly ${ }^{3} \mathrm{He},{ }^{85} \mathrm{Kr}$ ) pointing to presence of young water.

It also should be noted that the temporal patterns in nitrate concentration in some of the wells (wells 29 and 32 in particular) are not consistent with what is expected from steady state residence time distributions and may point tosome long-term transient behavior. Model structural error as a result of the assumption of steady-state LPM can also result in discrepancies between nitrate and tracer data. 


\section{Cumulative age distribution}

Under scenarios 1 and 2, where the nitrate record was used as a tracer,all wells (except 32) display the absence of a very young water component of less than 20 years in the age distribution of sampled water

532 (Figure 6). For two wells $(4,14)$, the youngest component of the groundwater age distribution is more 533 than 40 years old. Despite the number of age tracers, the cumulative age distribution is poorly constrained by Scenario 3.Scenario 3 suggests the presence of a significant portion of water younger than 50 years for wells 8,20, 32 and 35 - probably due to the greater reliance on ${ }^{3} \mathrm{H},{ }^{3} \mathrm{He}$ and ${ }^{85} \mathrm{Kr}$ data while this was not suggested by scenarios 1 and 2 due to the larger reliance on nitrate lag for those scenarios. The credible interval of the old fraction is relatively large $(0.2-0.4)$. The estimates of the mean age of the Inverse Gaussian component fall between 20 to 60 years, with a typical credible interval of 30 years. The IG standard deviation ranges from near zero to over 20 years in all wells, and to over 50 for wells 8,20 and 32 . The resultsthus show that the resulting cumulative age distributions are not well defined. Two of the three wells with no ${ }^{85} \mathrm{Kr}$ measurement ( 4 and 35 ) appear to be as well constrained by the other tracers as the other wells. The specific combination of tracer concentrations and low ${ }^{85} \mathrm{Kr}$ activitiesresults in little additional information revealed by the ${ }^{85} \mathrm{Kr}$ measurements.

544 Cumulative age distributions estimated by Scenario 1 (including nitrate) are mostly older (wells 8, 39, 20, 54535,32 ) and better defined, with narrower credible intervals. The differences with Scenario 3 results are 546 striking, showing that the nitrate data receivesmost of the weight in the likelihood function. Scenario 2 cumulative age distributions fallmostly in between the other scenarios.

\section{Nitrate}

552 Nitrate concentration predictions based on tracer data alone do not agree well with observed time 553 series (Figure 7). Using minimization of measured-modeled nitrate concentration difference, a multiplier 554 value of $x x$ was estimated. The credible intervals are adjusted by the nitrate multiplier to encompass the observations, but the trend slope is captured only for well 4. Uncertainty in the age distributions also leads to uncertainty in nitrate predictions, and the delay and trend of nitrate is not in agreement with the estimated age distributions. Based on tracer data alone, the models predict that nitrate will not exceed the MCL in any of the 8 wells studied. 
Nitrate predictions for Scenarios 1 and 2 largely overlap, because of the large number of nitrate measurements. Scenario 1 credible intervals are typically narrower than those of Scenario 2 . Nitrate trends are generally well captured, unless the nitrate time series is short (well 39) or outliers are present (well 29). The short time series of well 39 shows how the credible intervals of nitrate predictions before and after the period of observation quickly increase, resulting in butterfly-shaped graphs. This effect is also visible when tracer data are included, but to a lesser extent. Scenario 2 predicts that nitrate concentrations will exceed the $M C L$ in 2040in five wells (8, 14, 4, 35 and 32; Table 10), at probabilities between $8 \%$ (well 8 ) and $100 \%$ (well 32). Scenario 1 does not predict nitrate concentrations above the $\mathrm{MCL}$ in well 8, and predicts low probabilities (4\%-9\%) for $\mathrm{MCL}$ exceedances in wells 14 and 4 . Both scenarios predictthat the MCL will be exceeded in wells 35 and 32 at confidence levels of $84 \%$ or higher.A common feature of the Bayesian inference predictions of nitrate concentrations is a flattening of the nitrate trend, thanks to a flattening of the input curve beginning in about 1990. For wells 14 and

571 4in particular, this aspect avoids nitrate concentrations above the MCL that are predicted by 572 extrapolation of linear trend models.

573 It worth noting that one of the sources of uncertainty that is not considered in this study is the 574 uncertainty associated with the trend in the nitrate input function. Although a systematic bias 575 represented as a multiplier has been considered, there can also be uncertainties in the trends of nitrate 576 input that can affect the inference of LPM parameters and thus the projection. Because recharge 577 concentrations are composed of time-series that can take infinite forms and therefore can introduce 578 unbounded degrees of freedom, incorporating such uncertainties is challenging and requires innovative 579 approaches that could be a subject of future studies. It also should be noted that the effect of 580 denitrification can be included explicitly using a first order or zeroth order decay process (Green et al., 581 this issue), but that would have led to one additional parameter, which was intentionally avoided.

\section{Discussion}

583 Predicted nitrate concentrations based on both tracer and nitrate data have narrower credible intervals compared to when only nitrate is used to obtain travel time distributions. This means that inclusion of tracer data in effect selects a subset of plausible travel time distributions based on nitrate data that are also able to explain tracers. Because these set of outcomes are supported by several lines of evidence, they can be considered more reliable.

Predictions of nitrate concentrations all show a leveling off between the present and 2040, thanks to the leveling off of reconstructedhistorical nitrate loadings to groundwater since about 1990. The challenge for predicting when nitrate concentrations in pumped groundwater will level off, and at what level, lies in accurately estimating the age distribution of pumped groundwater. The uncertainties in the projection of magnitude and timing of flattening out stem from the uncertainties in travel time distribution, possible nitrate transformation and both historic and future nitrate inputs. The analysis of a combination of age tracers aids in constraining the delay of the arrival of the nitrate, linked to the mean age of the young fraction, and the ultimate level of nitrate concentrations, linked to the contribution of old, nitrate-free groundwater. In this study we show that including the historical nitrate time-series 
addition, theBayesian modeling approach allows for evaluation of the credibility of the age distribution and nitrate predictions. While model calibration might deterministically predict future nitrate concentrations to exceed the MCL or not, the credible intervals of the Bayesian approach allow calculation of the probability that the MCL will be exceeded.

The nitrate and tracer data presented here are modeled to providethe best estimate of the age distributionswith respect to reproducing both nitrate and tracer datapoints at these wells, but they are a snapshot in time(Visseretal.2013a). Furthermore, tracer input functions are variably affected by retardation in near-surface soil and the vadose zone. The conceptual time transfer model underlying the Bayesian inference in this study is inherently steady state.However, it should be noted that the nature of groundwater flow during the relevant period in the past is likely transient, due to factors such as increased irrigation, installation of new wells and changes in groundwater storage, which could have had a significant impact on the tracer concentrations. This likely explains some of the discrepancies between nitrate concentration records and what the LPM model can reproduce. In other settings, denitrification and other geochemical processes along groundwater flow paths might need to be considered explicitly (Visser et al., 2009a). Expanding into age distributions derived from numerical flow models and particle tracking (Burow et al., 2008a) can constrain the age distribution and nitrate source attribution under a variable land use history. Spatially distributed modeling, including land use changes in the capture zone of drinking water production wells, could predict decreasing nitrate concentrations if nitrate loading decreases due to urbanization. Random realizations of subsurface heterogeneity leading to variations of groundwater age distributions (Weissmann et al., 2002) are an alternative to assuming LPMs with presumed forms for assessing the uncertainty associated with predicting future nitrate trends. Transient groundwater conditions due to pumping for public water supply and irrigation may induce sudden shifts in the groundwater age distribution that are not captured by steady state models (Zuber et al., 2011)(Visseretal.2013a). Such shifts are a likely explanation for the sudden changes in the nitrate concentrations observed at these wells. Very few studies (e.g., Jeffrey Starn et al., 2014) have addressed the need for transient groundwater flow and transport models to accurately predict water quality trends. In principle, transient numerical models can easily be incorporated in the Bayesian framework, at the cost of higher computing times.

It should also be noted that one of the other factors that may impact the outcome of the presented results is the uncertainties associated with the historic input concentrations pattern, particularly the recharge concentrations of nitrate. Although the uncertainty in the magnitude of nitrate loading has been accounted for in the multiplier parameter, there are uncertainties in the shape (temporal pattern) of nitrate recharge concentrations that may have been neglected. Uncertainties in the input are actually uncertainties associated with time-series, and incorporating this type of uncertainty in a Bayesian framework using conventional methods is a challenging task. Developing innovative approaches to include time-series uncertainty in groundwater dating may therefore be a subject of future studies.

\section{Conclusions}

A Bayesian approach was applied to infer the key parameters of lumped parameter models, consisting of Inverse Gaussian (young) and Dirac (old) components. These components represent the groundwater 
age distribution at eight wells in Turlock, California, based on measured concentrations of multiple agetracers and historic time-series of observed nitrate concentrations. Low ${ }^{85} \mathrm{Kr}$ concentrations and apparent ${ }^{3} \mathrm{H} /{ }^{3} \mathrm{He}$ ages point to a relatively old modern fraction (40-50 years), diluted with pre-modern groundwater, corroborated by the onset and slope of increasing nitrate concentrations. Three scenarios were evaluated to study the ability of the Bayesian inference framework to reproduce measured tracer concentrations and nitrate, estimate groundwater age distributions, and predict nitrate concentrations: Scenario 1 includes both tracer and nitrate data, Scenario 2 includes nitrate data only, and Scenario 3 includes tracer data only. The obvious conclusion from our results is that including both nitrate and tracer data leads to good agreement between observed and modeled nitrate time series data and narrower credible intervals on future nitrate projections. Due to the number of nitrate observations, the age distribution model is largely constrained by the trend in the nitrate concentrations. However, the tracer data was first used to find an appropriate age distribution model.

It should be noted that overlooking the long-term transient nature of the flow field as a result of changes in irrigation and pumping patterns can contribute to some of the discrepancies between nitrate and tracer-based inferences of travel time distribution. Due to the lack of knowledge about these temporal variations in the past and the way they impact travel time distribution in a complex system, including them into the type of analysis carried out in this study is challenging.

654 Other potential future work is to develop a method to incorporate the uncertainties attributed to the pattern in recharge concentrations. This is particularly important for nitrate, as the way the nitrate loading rates are obtained using fertilizer sale data can introduce systematic biases in the temporal trend of loading which are not captured by the multiplier parameter. The threat of well closures due to nitrate concentrations increasing above the MCL has become a major concern for the drinking water supplies in the California Central Valley. In all wells studied here, predictions of nitrate concentrations show a leveling off between the present and 2040, thanks to the leveling off of reconstructedhistorical nitrate loadings to groundwater since about 1990. The risk of nitrate concentrations exceeding the MCL within 25 years, which could lead to well closures, may not be as high as present day trends in nitrate concentrations suggest.The challenge for predicting when nitrate concentrations in pumped groundwater will level off, and at what level, lies in accurately estimating the age distribution of pumped groundwater and in having knowledge of the historical nitrate loading to the groundwater.

\section{Acknowledgments}

667 Funding for the project came from the California State Water Resources Control Board Groundwater 668 Ambient Monitoring and Assessment (GAMA) Special Studies program. The researchers are also grateful 669 for the enthusiastic participation of the City of Turlock. Laboratory support from Michael Singleton, 670 Sarah Roberts, and Stephanie Uriostegui is gratefully acknowledged. This work performed under the 671 auspices of the U.S. Department of Energy by Lawrence Livermore National Laboratory under Contract 672 DE-AC52-07NA27344. This data was collected in collaboration with the U.S. Geological Survey, and 673 funded by the Groundwater Ambient Monitoring and assessment Program.LLNL-JRNL-677921 
676

677

678

679

680

681

682

683

684

685

686

687

688

689

690

691

692

693

694

695

696

697

698

699

700

701

702

703

704

705

706

707

708

709

710

711

712

713

714

715

716

717

718

719

Åkesson, M. et al., 2014. Constraining Age Distributions of Groundwater from Public Supply Wells in Diverse Hydrogeological Settings by Means of Environmental Tracers and Lumped-Parameter Modelling: A Case Study From Scania, Southern Sweden. Journal of Hydrology.

Alexander, R.B., Smith, R.A., 1990. County-level estimates of nitrogen and phosphorus fertilizer use in the United States, 1945 to 1985. 2331-1258, US Geological Survey; Books and Open-File Reports [distributor].

Althaus, R. et al., 2009. Noble gas tracers for characterisation of flow dynamics and origin of groundwater: A case study in Switzerland. Journal of Hydrology, 370(1-4): 64-72.

Arkley, R.J., 2009. The Geology, Geomorphology, and Soils of the San Joaquin Valley in the Vicinity of the Merced River, California. California Division of Mines and Geology. Bulletin 182.

Batlle-Aguilar, J., Orban, P., Dassargues, A., Brouyère, S., 2007. Identification of groundwater quality trends in a chalk aquifer threatened by intensive agriculture in Belgium. Hydrogeology Journal, 15(8): 1615.

Belitz, K., Fram, M.S., Johnson, T.D., 2015. Metrics for Assessing the Quality of Groundwater Used for Public Supply, CA, USA: Equivalent-Population and Area. Environmental Science \& Technology, 49(14): 8330-8338.

Böhlke, J.K., Denver, J.M., 1995. Combined use of groundwater dating, chemical, and isotopic analyses to resolve the history and fate of nitrate contamination in two agricultural watersheds, Atlantic coastal plain, Maryland. Water Resources Research, 31(9): 2319-2339.

Böhlke, J.K., Wanty, R., Tuttle, M., Delin, G., Landon, M., 2002. Denitrification in the recharge area and discharge area of a transient agricultural nitrate plume in a glacial outwash sand aquifer, Minnesota. Water Resources Research, 38(7): -.

Broers, H.P., Van der Grift, B., 2004. Regional monitoring of temporal changes in groundwater quality. Journal of Hydrology, 296(1-4): 192-220.

Burow, K., Dubrovsky, N., Shelton, J., 2007. Temporal trends in concentrations of DBCP and nitrate in groundwater in the eastern San Joaquin Valley, California, USA. Hydrogeology Journal, 15(5): 991-1007.

Burow, K.R. et al., 2008a. Simulations of ground-water flow and particle pathline analysis in the zone of contribution of a public-supply well in Modesto, eastern San Joaquin Valley, California. US Department of the Interior, US Geological Survey.

Burow, K.R., Shelton, J.L., Dubrovsky, N.M., 2008b. Regional nitrate and pesticide trends in ground water in the eastern San Joaquin Valley, California. Journal of Environmental Quality, 37(S5): 249-263.

Busenberg, E., Plummer, L.N., 1992. Use of Chlorofluorocarbons $\left(\mathrm{CCl}_{3} \mathrm{~F}_{\text {and }} \mathrm{CCl}_{2} \mathrm{~F}_{2}\right)$ as Hydrologic Tracers and Age-Dating Tools: the Alluvium and Terrace System of Central Oklahoma. Water Resources Research, 28(9): 2257-2283.

Busenberg, E., Plummer, L.N., 2000. Dating young groundwater with sulfur hexafluoride: Natural and anthropogenic sources of sulfur hexafluoride. Water Resources Research, 36(10): 3011-3030.

California, U.o., 2012. Nitrogen Efficiency in Almond Production. Retrieved from http://cesanjoaquin.ucdavis.edu/newsletters/Field Notes Newsletter43137.pdf.

Clarke, W.B., Jenkins, W.J., Top, Z., 1976. Determination of tritium by mass spectrometric measurement of ${ }^{3} \mathrm{He}$. The International Journal of Applied Radiation and Isotopes, 27(9): 515-522.

Corcho Alvarado, J.A. et al., 2007. Constraining the age distribution of highly mixed groundwater using ${ }^{39} \mathrm{Ar}$ : A multiple environmental tracer $\left({ }^{3} \mathrm{H} /{ }^{3} \mathrm{He},{ }^{85} \mathrm{Kr},{ }^{39} \mathrm{Ar}\right.$, and $\left.{ }^{14} \mathrm{C}\right)$ study in the semiconfined Fontainebleau Sands Aquifer (France). Water Resources Research, 43(3): W03427. 
Esser, B. et al., 2002. Nitrate contamination in California groundwater: an integrated approach to basin assessment and resource protection. US Department of Energy Lawrence Livermore National Laboratory.

Fontes, J.C., Garnier, J.M., 1979. Determination of the initial ${ }^{14} \mathrm{C}$ activity of the total dissolved carbon: a review of the existing model and a new approach. Water Resources Research, 15(2): 399-413.

Geweke, J., 1992. Evaluating the accuracy of sampling-based approaches to calculating posterior moments. In: Bernardo, J.M., Berger, J., Dawid, A.P., Smith, J.F.M. (Eds.), Bayesian Statistics 4. Oxford University Press, pp. 169-193.

Geweke, J., Tanizaki, H., 2001. Bayesian estimation of state-space models using the Metropolis-Hastings algorithm within Gibbs sampling. Computational Statistics \& Data Analysis, 37(2): 151-170.

Green, C.T., Böhlke, J.K., Bekins, B.A., Phillips, S.P., 2010. Mixing effects on apparent reaction rates and isotope fractionation during denitrification in a heterogeneous aquifer. Water Resour. Res., 46(8): W08525.

Green, C.T., Fisher, L.H., Bekins, B.A., 2008a. Nitrogen fluxes through unsaturated zones in five agricultural settings across the United States. Journal of environmental quality, 37(3): 10731085.

Green, C.T. et al., 2008b. Limited Occurrence of Denitrification in Four Shallow Aquifers in Agricultural Areas of the United States. Journal of Environmental Quality, 37(3): 994-1009.

Green, C.T., Zhang, Y., Jurgens, B.C., Starn, J.J., Landon, M.K., 2014. Accuracy of travel time distribution (TTD) models as affected by TTD complexity, observation errors, and model and tracer selection. Water Resources Research, 50(7): 6191-6213.

Hansen, B., Thorling, L., Dalgaard, T., Erlandsen, M., 2010. Trend reversal of nitrate in Danish groundwater-a reflection of agricultural practices and nitrogen surpluses since 1950. Environmental science \& technology, 45(1): 228-234.

Harter, T., 2012. Addressing Nitrate in California's Drinking Water: With a Focus on Tulare Lake Basin and Salinas Valley Groundwater: Report for the State Water Resources Control Board Report to the Legislature. Center for Watershed Sciences, University of California, Davis.

Hollocher, T.C., 1984. Source of the oxygen atoms of nitrate in the oxidation of nitrite by Nitrobacter agilis and evidence against a $\mathrm{P} \square \mathrm{O} \square \mathrm{N}$ anhydride mechanism in oxidative phosphorylation. Archives of Biochemistry and Biophysics, 233(2): 721-727.

Jeffrey Starn, J., Green, C.T., Hinkle, S.R., Bagtzoglou, A.C., Stolp, B.J., 2014. Simulating Water-Quality Trends in Public-Supply Wells in Transient Flow Systems. Groundwater, 52(S1): 53-62.

Jenden, P.D., Kaplan, I.R., Poreda, R., Craig, H., 1988. Origin of nitrogen-rich natural gases in the California Great Valley: Evidence from helium, carbon and nitrogen isotope ratios. Geochimica Et Cosmochimica Acta, 52(4): 851-861.

Jurgens, B.C., Böhlke, J.K., Eberts, S.M., 2012. TracerLPM (Version 1): An Excel ${ }^{\circledR}$ workbook for interpreting groundwater age distributions from environmental tracer data: U.S. Geological Survey Techniques and Methods Report 4-F3, U.S. Geological Survey, Reston, Virginia.

Kana, T.M. et al., 1994. Membrane Inlet Mass Spectrometer for Rapid High-Precision Determination of $\mathrm{N}_{2}, \mathrm{O}_{2}$, and Ar in Environmental Water Samples. Analytical Chemistry, 66(23): 4166-4170.

Kendall, C., 1998. Tracing nitrogen sources and cycling in catchments. In Isotope Tracers in Catchment Hydrology (ed. C. Kendall and J. J. McDonnell), pp. 519-576. Elsevier. .

Kourakos, G., Klein, F., Cortis, A., Harter, T., 2012. A groundwater nonpoint source pollution modeling framework to evaluate long-term dynamics of pollutant exceedance probabilities in wells and other discharge locations. Water Resources Research, 48(6): W00L13.

Kulongoski, J.T. et al., 2013. Volatile fluxes through the Big Bend section of the San Andreas Fault, California: Helium and carbon-dioxide systematics. Chemical Geology, 339(0): 92-102. 
Lamontagne, S., 2002. Groundwater delivery rate of nitrate and predicted change in nitrate concentration in Blue Lake, South Australia. Marine and Freshwater Research, 53(7): 1129-1142.

Lehmann, B.E. et al., 2003. A comparison of groundwater dating with $81 \mathrm{Kr}, 36 \mathrm{Cl}$ and $4 \mathrm{He}$ in four wells of the Great Artesian Basin, Australia. Earth and Planetary Science Letters, 211(3-4): 237-250.

Liao, L., Green, C.T., Bekins, B.A., Böhlke, J.K., 2012. Factors controlling nitrate fluxes in groundwater in agricultural areas. Water Resour. Res., 48: W00L09.

Liao, Z., Osenbrück, K., Cirpka, O.A., 2014. Non-stationary nonparametric inference of river-togroundwater travel-time distributions. Journal of Hydrology, 519, Part D(0): 3386-3399.

Loosli, H.H., 1983. A dating method with ${ }^{39}$ Ar. Earth and Planetary Science Letters, 63(1): 51-62.

Loosli, H.H., Lehmann, B.E., Balderer, W., 1989. Argon-39, argon-37 and krypton-85 isotopes in Stripa groundwaters. Geochimica Et Cosmochimica Acta, 53(8): 1825-1829.

MacDonald, A.M., Darling, W.G., Ball, D.F., Oster, H., 2003. Identifying trends in groundwater quality using residence time indicators: an example from the Permian aquifer of Dumfries, Scotland. Hydrogeology Journal, 11(4): 504-517.

Maloszewski, P., Zuber, A., 1982. Determining the turnover time of groundwater systems with the aid of environmental tracers. 1. Models and their applicability. Journal of Hydrology, 57(3-4): 207-231.

Maloszewski, P., Zuber, A., 1993. Principles and practice of calibration and validation of mathematical models for the interpretation of environmental tracer data in aquifers. Advances in Water Resources, 16(3): 173.

Maloszewski, P., Zuber, A., 1998. A general lumped parameter model for the interpretation of tracer data and transit time calculation in hydrologic systems - Comments. Journal of Hydrology, 204(14): 297-300.

Mariotti, A., Landreau, A., Simon, B., 1988. $15 \mathrm{~N}$ isotope biogeochemistry and natural denitrification process in groundwater: Application to the chalk aquifer of northern France. Geochimica et Cosmochimica Acta, 52(7): 1869-1878.

Massoudieh, A., Ginn, T.R., 2011. The theoretical relation between unstable solutes and groundwater age. Water Resour. Res., 47(10): W10523.

Massoudieh, A., Sharifi, S., Solomon, D.K., 2012. Bayesian evaluation of groundwater age distribution using radioactive tracers and anthropogenic chemicals. Water Resour. Res., 48(9): W09529.

Massoudieh, A., Visser, A., Sharifi, S., Broers, H.P., 2014. A Bayesian modeling approach for estimation of a shape-free groundwater age distribution using multiple tracers. Applied Geochemistry(0).

McCallum, J.L., Engdahl, N.B., Ginn, T.R., Cook, P.G., 2014. Nonparametric estimation of groundwater residence time distributions: What can environmental tracer data tell us about groundwater residence time? Water Resources Research, 50(3): 2022-2038.

McMahon, P.B., Chapelle, F.H., 2008. Redox Processes and Water Quality of Selected Principal Aquifer Systems. Ground Water, 46(2): 259-271.

McNab, W.W., Singleton, M.J., Moran, J.E., Esser, B.K., 2007. Assessing the impact of animal waste lagoon seepage on the geochemistry of an underling shallow aquifer. Environmental Science and Technology, 41(3): 753-758.

Metropolis, N., Rosenbluth, A.W., Rosenbluth, M.N., Teller, A.H., Teller, E., 1953. Equation of State Calculations by Fast Computing Machines. The Journal of Chemical Physics, 21(6): 1087-1092.

Moore, K.B., Ekwurzel, B., Esser, B.K., Hudson, G.B., Moran, J.E., 2006. Sources of groundwater nitrate revealed using residence time and isotope methods. Applied Geochemistry, 21(6): 1016-1029.

Moran, J. et al., 2008. California GAMA Program: Development of a Field Deployable Dissolved Gas Extraction Apparatus. Lawrence Livermore National Laboratory. UCRL-TR-407175

Oeschger, H. et al., 1974. 39Ar dating of groundwater, Isotope Techniques in Groundwater Hydrology. International Atomic Energy Agency, Vienna, pp. 179-190. 
Orban, P. et al., 2010. Regional transport modelling for nitrate trend assessment and forecasting in a chalk aquifer. Journal of Contaminant Hydrology, 118(1-2): 79-93.

Pinault, J.L., Dubus, I.G., 2008. Stationary and non-stationary autoregressive processes with external inputs for predicting trends in water quality. Journal of Contaminant Hydrology, 100(1-2): 22-29.

Plummer, L. et al., 2012. Old groundwater in parts of the upper Patapsco aquifer, Atlantic Coastal Plain, Maryland, USA: evidence from radiocarbon, chlorine-36 and helium-4. Hydrogeology Journal, 20(7): 1269-1294.

Plummer, L.N. et al., 2001. Groundwater residence times in Shenandoah National Park, Blue Ridge Mountains, Virginia, USA: a multi-tracer approach. Chemical Geology, 179(1-4): 93-111.

Poreda, R.J., Cerling, T.E., Salomon, D.K., 1988. Tritium and Helium-Isotopes as Hydrologic Tracers in a Shallow Unconfined Aquifer. Journal of Hydrology, 103(1-2): 1-9.

Ruddy, B.C., Lorenz, D.L., Mueller, D.K., 2006. County-level estimates of nutrient inputs to the land surface of the conterminous United States, 1982-2001. US Department of the Interior, US Geological Survey.

Schlosser, P., Stute, M., Dorr, H., Sonntag, C., Munnich, K.O., 1988. Tritium/ ${ }^{3}$ He Dating of Shallow Groundwater. Earth and Planetary Science Letters, 89(3-4): 353-362.

Singleton, M.J. et al., 2007. Saturated zone denitrification: Potential for natural attenuation of nitrate contamination in shallow groundwater under dairy operations. Environmental Science and Technology, 41(3): 759-765.

Singleton, M.J., Moran, J.E., 2010. Dissolved noble gas and isotopic tracers reveal vulnerability of groundwater in a small, high-elevation catchment to predicted climate changes. Water Resour. Res., 46: W00F06.

Smethie, J.W.M., Solomon, D.K., Schiff, S.L., Mathieu, G.G., 1992. Tracing groundwater flow in the Borden aquifer using krypton-85. Journal of Hydrology, 130(1-4): 279-297.

Solomon, D.K., Genereux, D.P., Plummer, L.N., Busenberg, E., 2010. Testing mixing models of old and young groundwater in a tropical lowland rain forest with environmental tracers. Water Resources Research, 46.

Squillace, P.J., Scott, J.C., Moran, M.J., Nolan, B.T., Kolpin, D.W., 2002. VOCs, pesticides, nitrate, and their mixtures in groundwater used for drinking water in the United States. Environmental Science \& Technology, 36(9): 1923-1930.

St-Jean, G., 2003. Automated quantitative and isotopic (13C) analysis of dissolved inorganic carbon and dissolved organic carbon in continuous-flow using a total organic carbon analyser. Rapid Communications in Mass Spectrometry, 17(5): 419-428.

Stanislaus County, 2012. Stanislaus County Agriculture Crop Report. Retrieved from http://www.stanag.org/ag/croprpts/croppdf/2012-crop-report.pdf.

Stuart, M.E., Chilton, P.J., Kinniburgh, D.G., Cooper, D.M., 2007. Screening for long-term trends in groundwater nitrate monitoring data. Quarterly Journal of Engineering Geology and Hydrogeology, 40(4): 361-376.

Sültenfuß, J., Purtschert, R., Führböter, J., 2011. Age structure and recharge conditions of a coastal aquifer (northern Germany) investigated with ${ }^{39} \mathrm{Ar},{ }^{14} \mathrm{C},{ }^{3} \mathrm{H}$, He isotopes and Ne. Hydrogeology Journal, 19(1): 221-236.

Surano, K.A. et al., 1992. Helium-3 mass spectrometry for low-level tritium analysis of environmental samples. Journal of Radioanalytical and Nuclear Chemistry, 161(2): 443-453.

Tesoriero, A.J. et al., 2007. Linking ground-water age and chemistry data along flow paths: Implications for trends and transformations of nitrate and pesticides. Journal of Contaminant Hydrology, 94(1-2): 139.

Turlock Groundwater Basin Association, 2008. Turlock Groundwater Basin, Groundwater Management Plan, prepared for Turlock Irrigation District. Retrieved from: 
http://www.water.ca.gov/urbanwatermanagement/2010uwmps/Turlock,\%20City\%20of/Turlock Groundwater Management Plan+Appendices.pdf.

Visser, A., Broers, H., Van der Grift, B., Bierkens, M., 2007a. Demonstrating trend reversal of groundwater quality in relation to time of recharge determined by $3 \mathrm{H} / 3 \mathrm{He}$. Environmental Pollution, 148(3): 797-807.

Visser, A., Broers, H.P., Heerdink, R., Bierkens, M.F.P., 2009a. Trends in pollutant concentrations in relation to time of recharge and reactive transport at the groundwater body scale. Journal of Hydrology(3-4): 427-439.

Visser, A., Broers, H.P., Purtschert, R., Sültenfuß, J., de Jonge, M., 2013a. Groundwater age distributions at a public drinking water supply well field derived from multiple age tracers $\left({ }^{85} \mathrm{Kr},{ }^{3} \mathrm{H} /{ }^{3} \mathrm{He}\right.$, and ${ }^{39} \mathrm{Ar}$ ). Water Resources Research, 49(11): 7778-7796.

Visser, A., Broers, H.P., Purtschert, R., Sültenfuß, J., De Jonge, M., 2013b. Groundwater age distributions at a public drinking water supply well field derived from multiple age tracers $\left({ }^{85} \mathrm{Kr},{ }^{3} \mathrm{H} /{ }^{3} \mathrm{He}\right.$, noble gases and ${ }^{39} \mathrm{Ar}$ ). Water Resources Research, in review.

Visser, A., Broers, H.P., Van der Grift, B., Bierkens, M.F.P., 2007b. Demonstrating Trend Reversal of Groundwater Quality in Relation to Time of Recharge determined by ${ }^{3} \mathrm{H} /{ }^{3} \mathrm{He}$. Environmental Pollution, 148 (3): 797-807.

Visser, A. et al., 2009b. Comparison of methods for the detection and extrapolation of trends in groundwater quality. Journal of Environmental Monitoring, 11(11): 2030-2043.

Visser, A. et al., 2014a. Intercomparison of tritium and noble gases analyses, $3 \mathrm{H} / 3 \mathrm{He}$ ages and derived parameters excess air and recharge temperature. Applied Geochemistry, 50: 130-141.

Visser, A. et al., 2014b. Intercomparison of tritium and noble gases analyses, apparent ${ }^{3} \mathrm{H} /{ }^{3} \mathrm{He}$ ages and other derived parameters. Applied Geochemistry, 50: 130-141.

Visser, A., Moran, J.E., Aql, R., Singleton, M.J., Esser, B.K., 2013c. California GAMA Special Study: Examination of Water Quality in "Tritium-Dead" Drinking Water Wells. LLNL-TR- 558107. Lawrence Livermore National Laboratory. $54 \mathrm{p}$.

Visser, A. et al., 2013d. A membrane inlet mass spectrometry system for noble gases at natural abundances in gas and water samples. Rapid Communications in Mass Spectrometry, 27(21): $2472-2482$.

Vogel, J.C., Talma, A.S., Heaton, T.H.E., 1981. Gaseous nitrogen as evidence for denitrification in groundwater. Journal of Hydrology, 50: 191-200.

Wassenaar, L.I., Hendry, M.J., Harrington, N., 2006. Decadal geochemical and isotopic trends for nitrate in a transboundary aquifer and implications for agricultural beneficial management practices. Environmental Science and Technology, 40(15): 4626-4632.

Weissmann, G.S., Zhang, Y., LaBolle, E.M., Fogg, G.E., 2002. Dispersion of groundwater age in an alluvial aquifer system. Water Resources Research, 38(10): - .

Yoshinari, T., Wahlen, M., 1985. Oxygen isotope ratios in $\mathrm{N} 2 \mathrm{O}$ from nitrification at a wastewater treatment facility. Nature, 317(6035): 349-350.

Young, C.P., Oakes, D.B., Wilkinson, W.B., 1976. Prediction of Future Nitrate Concentrations in Ground Watera. Ground Water, 14(6): 426-438.

Zuber, A., Różański, K., Kania, J., Purtschert, R., 2011. On some methodological problems in the use of environmental tracers to estimate hydrogeologic parameters and to calibrate flow and transport models. Hydrogeology Journal, 19(1): 53-69. 


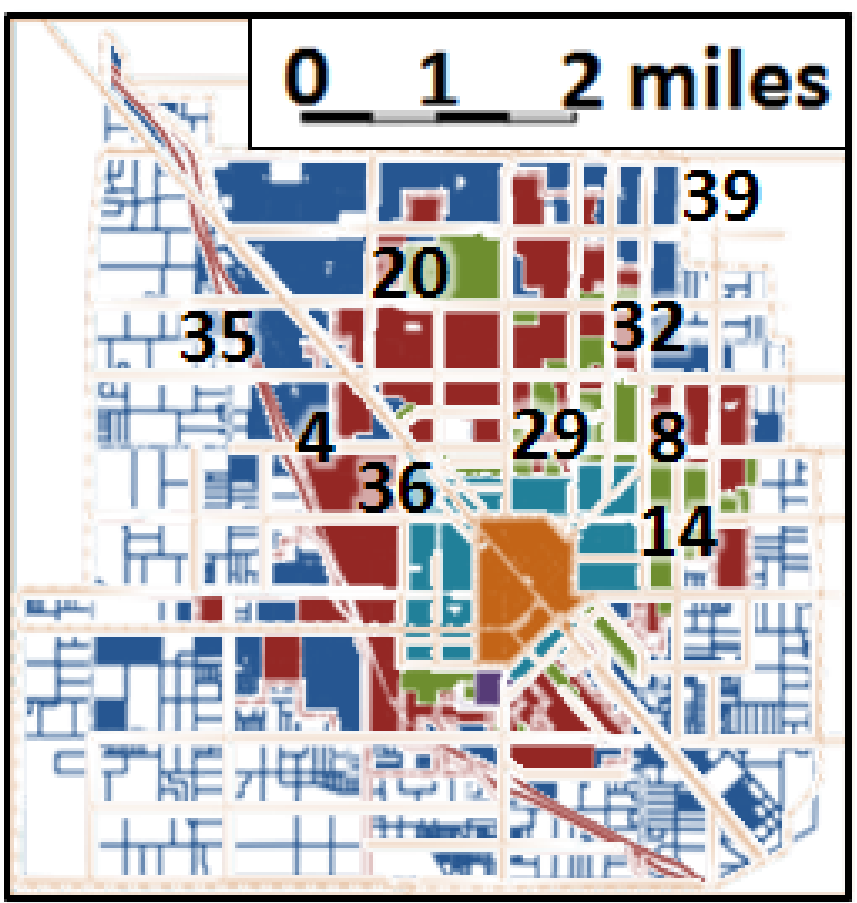

Year:

1907

1922

1943

1962

1992

2008

Figure 1: Land use pattern in the Turlock area from 1907-2008. Colored areas show the encroachment of locations. 


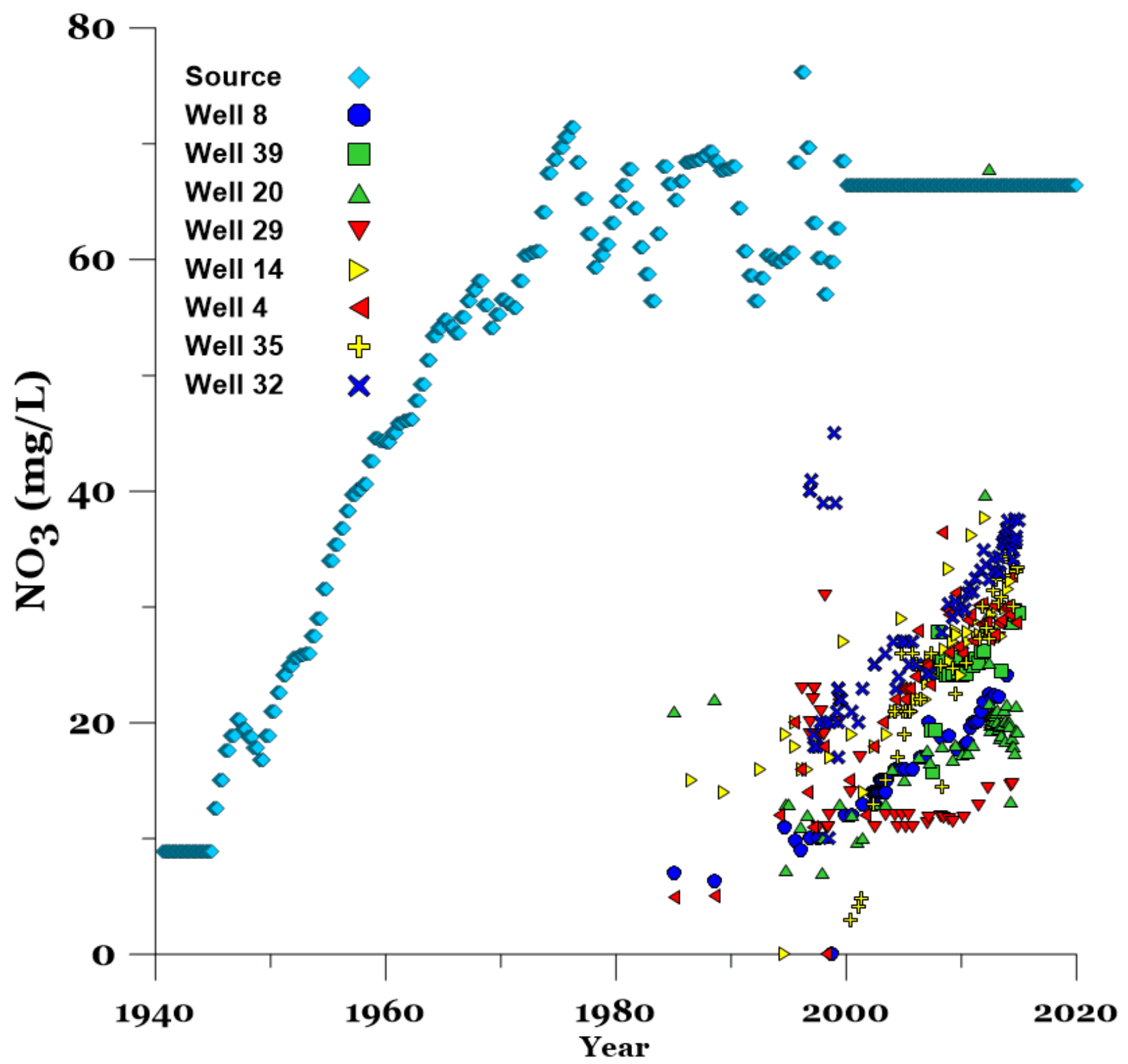

Figure 2: Nitrate input into groundwater estimated for nearby Modesto (Burow et al., 2008b) and observed nitrate concentrations in eight wells in Turlock (data obtained from California State Water Board GeoTrackerGAMAwebsite: geotracker.waterboards.ca.gov/gama).

917

918

919

920

921 
$\delta^{15} \mathrm{~N}$ vs $\delta^{18} \mathrm{O}$

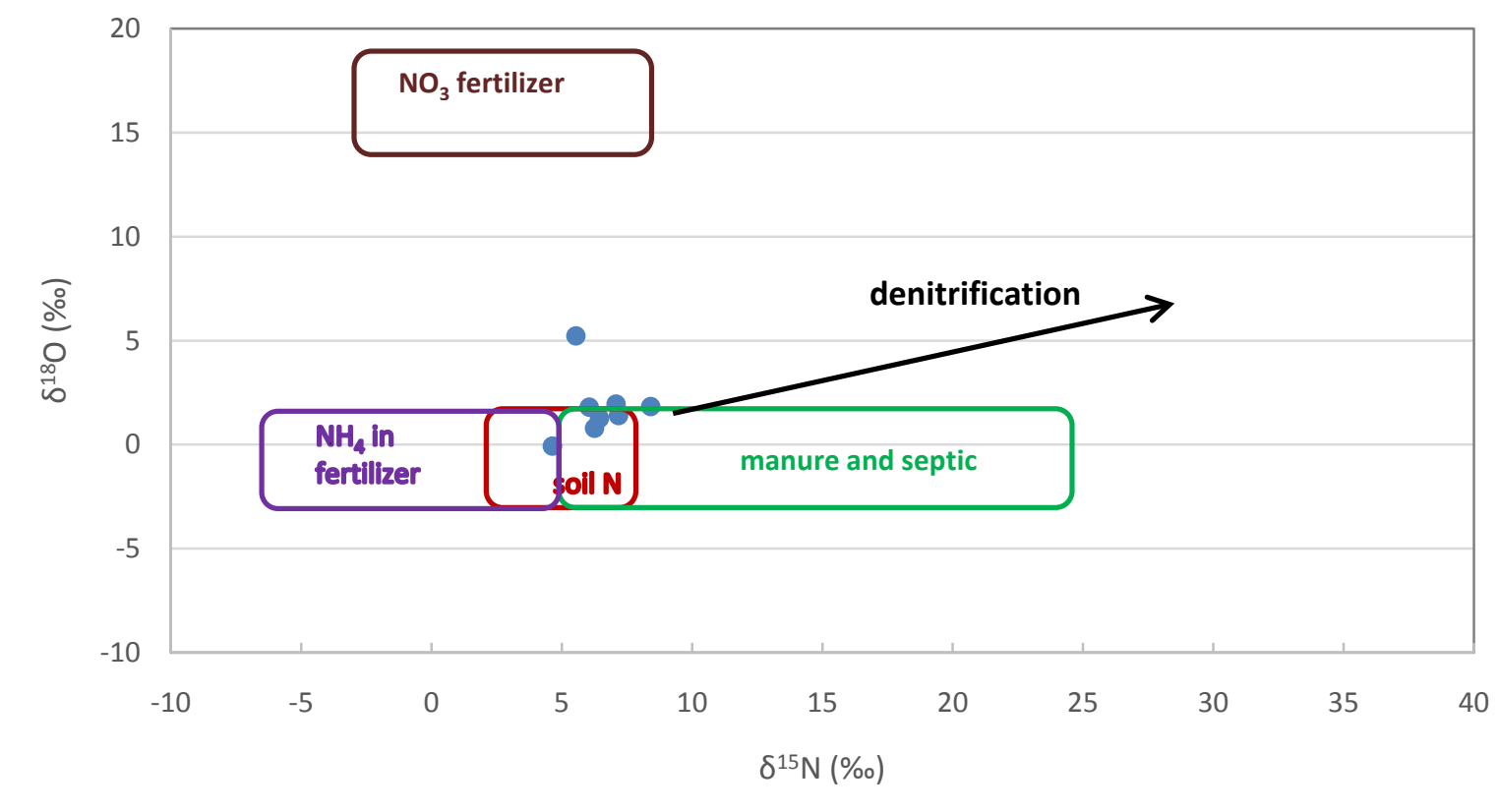

924

925 Figure 3: Plot of $\delta^{15} \mathrm{~N}$ versus $\delta^{18} \mathrm{O}$ of nitrate, with fields for common sources based on Kendall (1998).

926 Fields shown are adjusted for the local water $\delta^{18} \mathrm{O}$ signature for nitrified sources. 

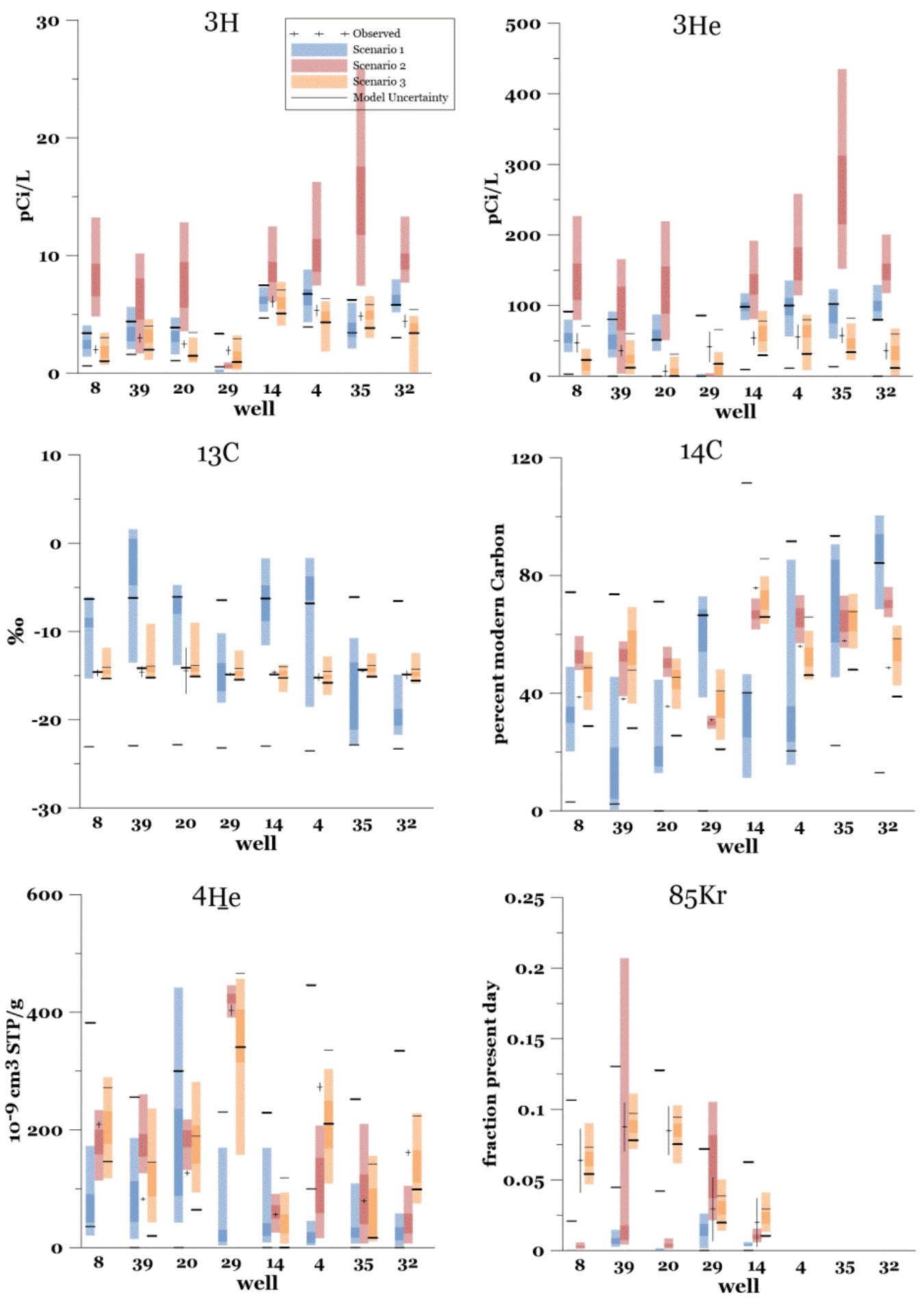

929 Figure 4: Measured tracer concentrations (symbols) with measurement uncertainty (vertical lines), 930 together with Bayesian inference results showing 50\% (dark shaded) and 95\% (light shaded) credible intervals of modeled tracer concentrations, and standard devation of model uncertainty (horizontal lines) plotted around the measured values. The standard deviation can be estimated only for the tracers used in each scenario. 

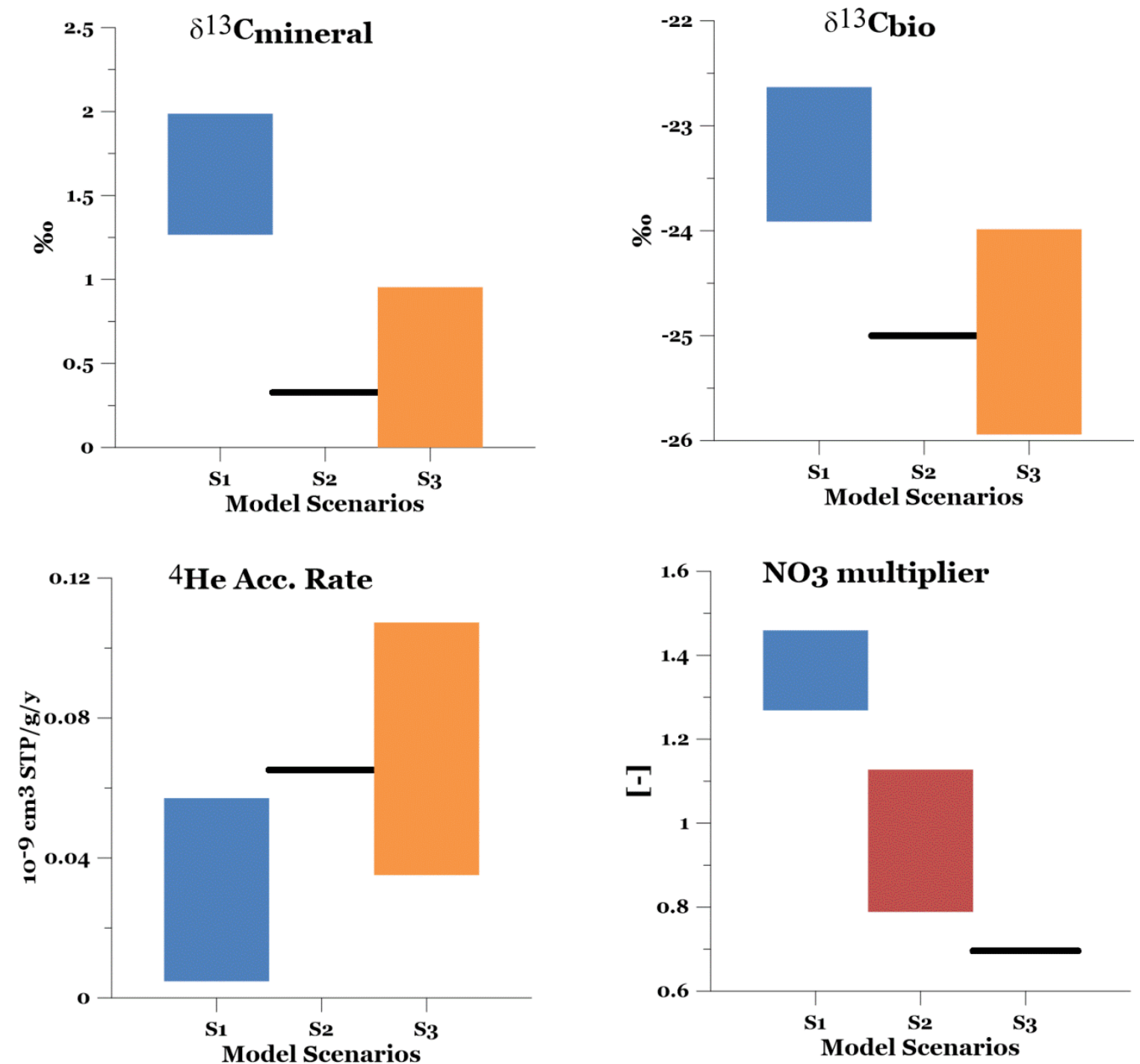

936 Figure 5: 95\% credible intervals of common model parameters for Scenario 1 (tracers+nitrate, blue), 937 Scenario 2 (nitrate only, red) and orange (tracers only, orange). 

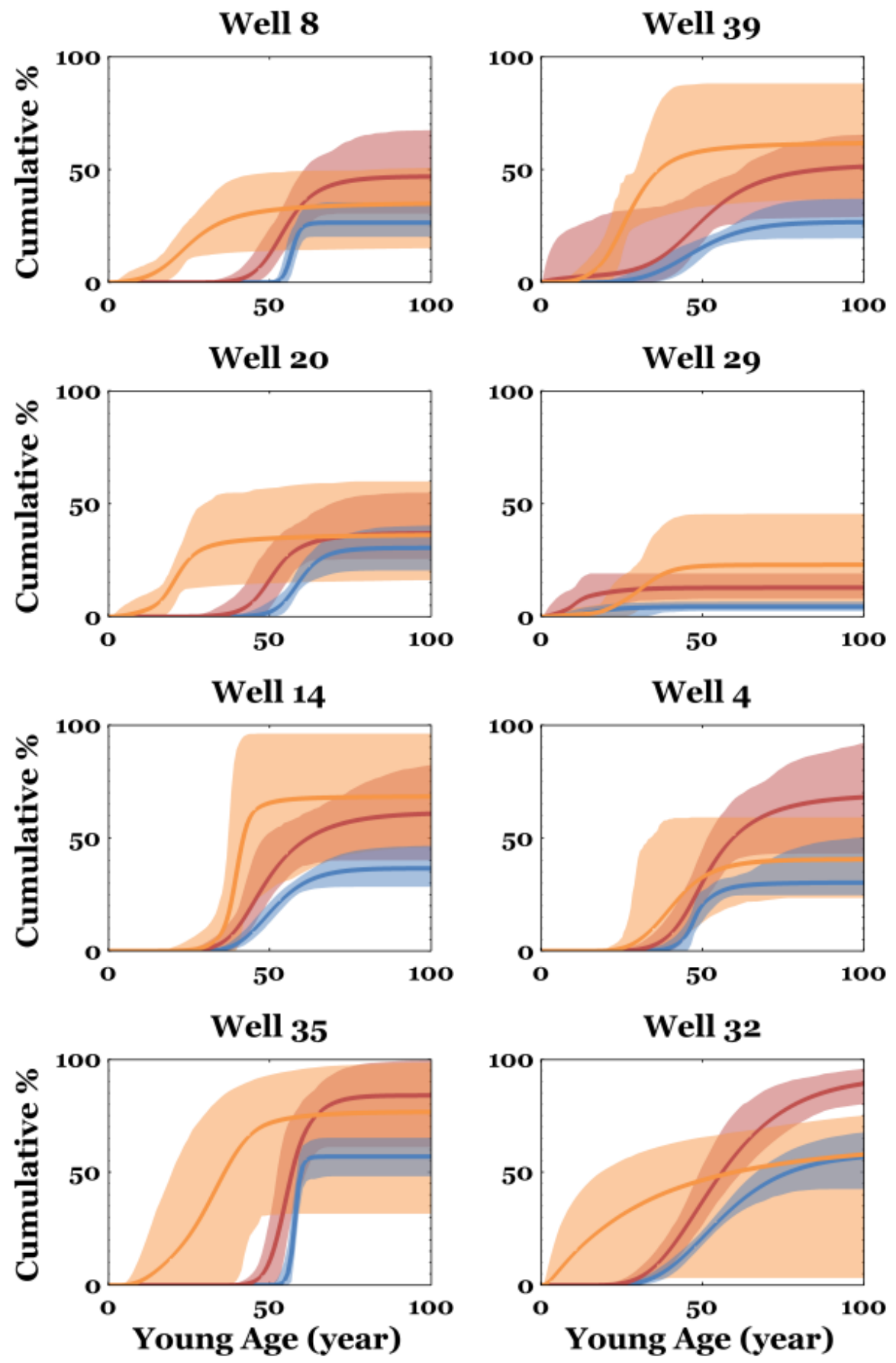

941 Figure 6: Cumulative age distributions for eight wells in Turlock, estimated by Scenario 1 (blue,

942 tracers+nitrate), Scenario 2 (red, nitrate only) or Scenario 3 (orange, tracers only). See text for a more 943 complete description of the 3 scenarios and predictions. 


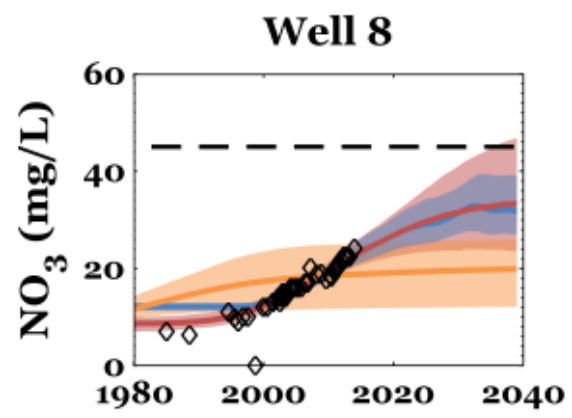

Well 20

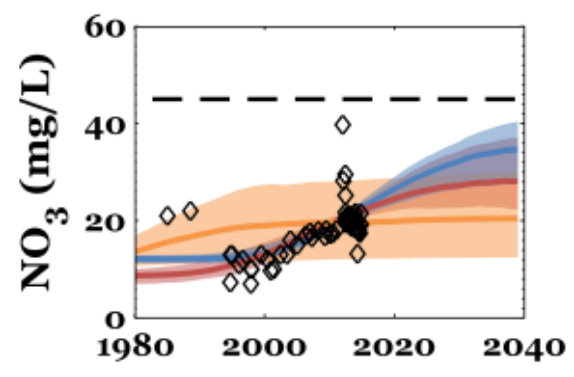

Well 14
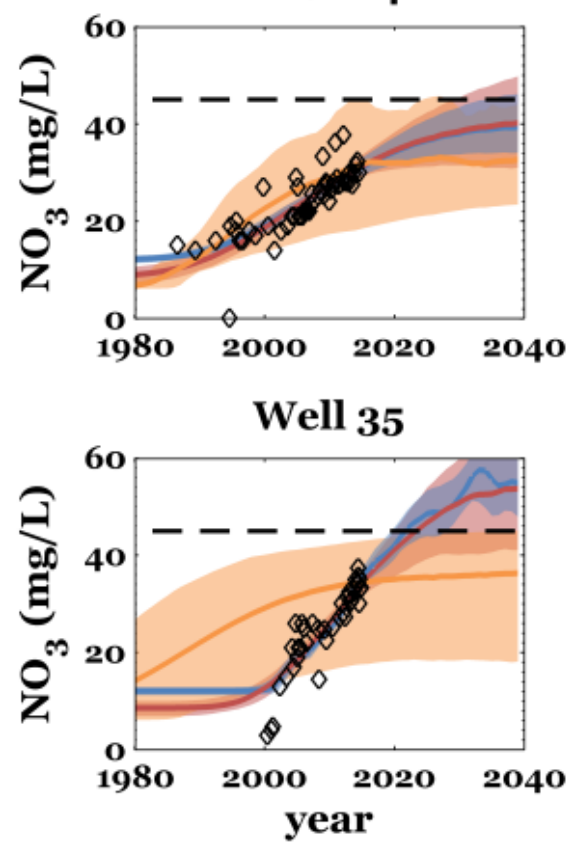

Well 39

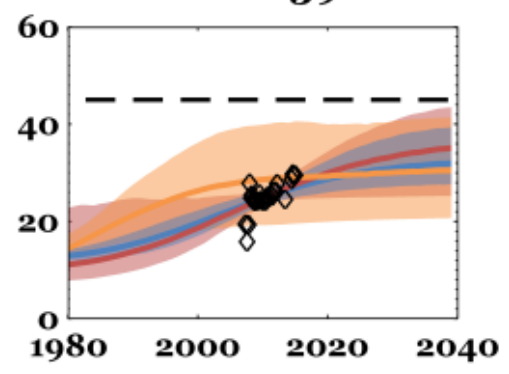

Well 29

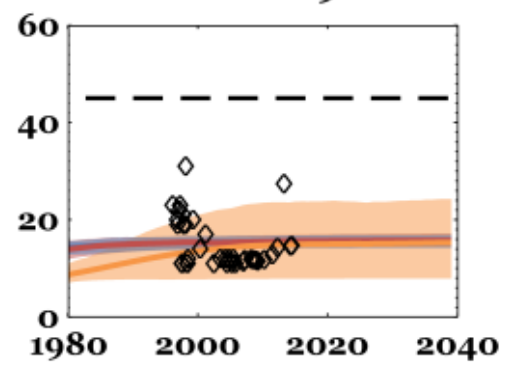

Well 4

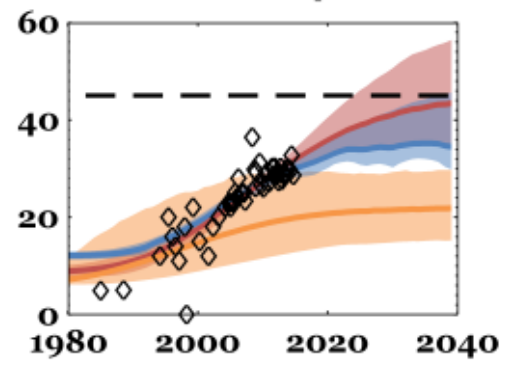

Well 32

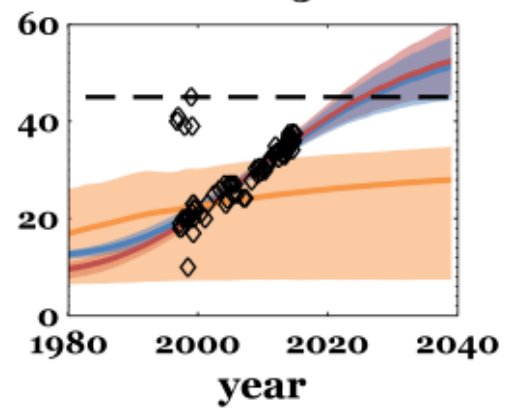

Figure 7: Observed nitrate concentrations (symbols) and median (colored line) and $95 \%$ credible 947 intervals (shaded areas) of predicted nitrate concentrations for eight wells in Turlock. Colors represent 948 Scenario 1 (blue, tracers+nitrate), Scenario 2 (red, nitrate only) or Scenario 3 (orange, tracers only).In 949 scenario 3 the nitrate multiplier was deterministically estimated by minimizing the difference between 950 measured and modeled nitrate data. 
Table 1: Well Characteristics

\begin{tabular}{|c|c|c|c|c|c|}
\hline \multirow{2}{*}{ Well } & \multirow{2}{*}{$\begin{array}{c}\text { Elevation } \\
(\mathrm{m})\end{array}$} & \multicolumn{3}{|c|}{ Screen Depth } & \multirow{2}{*}{$\begin{array}{c}\text { Collection } \\
\text { Date }\end{array}$} \\
\hline & & top (m) & bottom $(m)$ & length $(m)$ & \\
\hline 8 & 111 & 107 & 128 & 21 & 30-Jun-2014 \\
\hline 39 & 113 & 76 & 111 & 35 & 1-Jul-2014 \\
\hline 20 & 106 & 49 & 55 & 18 & 1-Jul-2014 \\
\hline 29 & 100 & 62 & 99 & 61 & 1-Jul-2014 \\
\hline 36 & 92 & 88 & 174 & 85 & 1-Jul-2014 \\
\hline 14 & 111 & 43 & 79 & 37 & 30-Jun-2014 \\
\hline 4 & 100 & 48 & 104 & 55 & 2-Jul-2014 \\
\hline 35 & 99 & 62 & 148 & 85 & 2-Jul-2014 \\
\hline 32 & 113 & 59 & 94 & 72 & 2-Jul-2014 \\
\hline
\end{tabular}


Table 2: Model parameters

\begin{tabular}{|c|c|c|c|c|c|c|}
\hline \multirow[t]{2}{*}{ Parameter } & \multirow[t]{2}{*}{ Description } & \multirow[t]{2}{*}{ Unit } & \multicolumn{3}{|c|}{ Scenario } & \multirow[t]{2}{*}{ Type } \\
\hline & & & 1 & 2 & 3 & \\
\hline${ }^{13} \mathrm{C}_{\min }$ & ${ }^{13} \mathrm{C}$ signature of carbonate mineral & $\%$ & Yes & No & Yes & Common (1) \\
\hline${ }^{13} \mathrm{C}_{\text {bio }}$ & ${ }^{13} \mathrm{C}$ signature of soil carbon dioxide & $\%$ & Yes & No & Yes & Common (1) \\
\hline${ }^{4} \mathrm{He}$ acc. rate & $4 \mathrm{He}$ accumulation rate & $10^{-9} \mathrm{~cm}^{3} \mathrm{STP} / \mathrm{g}$ & Yes & No & Yes & Common (1) \\
\hline $\mathrm{NO}_{3}$ mult. & Nitrate multiplier & - & Yes & Yes & No & Common (1) \\
\hline$f_{\min }$ & Fraction mineral carbon & - & Yes & No & Yes & Well specific (8) \\
\hline$f_{\text {old }}$ & Fraction old groundwater & - & Yes & Yes & Yes & Well specific (8) \\
\hline$\mu_{\tau, \text { old }}$ & Mean age of old groundwater component & Years & Yes & No & Yes & Well specific (8) \\
\hline$\mu_{\tau, \text { young }}$ & Mean age of Inverse Gaussian age distribution & Years & Yes & Yes & Yes & Well specific (8) \\
\hline$\sigma_{\tau, \text { young }}$ & Standard deviation of Inverse Gaussian age distribution & Years & Yes & Yes & Yes & Well specific (8) \\
\hline$\sigma_{\text {tracer }}$ & Standard deviation of model uncertainty & Same as tracer & Yes & No & Yes & Tracer specific (6) \\
\hline$\sigma_{\mathrm{NO} 3}$ & Standard deviation of model uncertainty & $\mathrm{mg} / \mathrm{L}$ & Yes & Yes & No & Nitrate specific (1) \\
\hline
\end{tabular}


Table 3: Measurements: Cations, Anions and Nitrate

\begin{tabular}{|c|c|c|c|c|c|c|c|c|c|c|c|}
\hline & \multicolumn{4}{|l|}{ Cations } & \multicolumn{7}{|c|}{ Anions and Nitrate Trends } \\
\hline \multirow{3}{*}{ Well } & \multirow{3}{*}{$\begin{array}{c}\mathrm{Na} \\
(\mathrm{mg} / \mathrm{L}) \\
\end{array}$} & \multirow{3}{*}{$\begin{array}{c}\mathbf{K} \\
(\mathrm{mg} / \mathrm{L}) \\
\end{array}$} & \multirow{3}{*}{$\begin{array}{c}\mathrm{Mg} \\
(\mathrm{mg} / \mathrm{L}) \\
\end{array}$} & \multirow{3}{*}{$\begin{array}{c}\mathrm{Ca} \\
(\mathrm{mg} / \mathrm{L}) \\
\end{array}$} & \multirow{3}{*}{$\begin{array}{c}\text { Chloride } \\
(\mathrm{mg} / \mathrm{L}) \\
\end{array}$} & \multirow{3}{*}{$\begin{array}{l}\text { Sulfate } \\
\text { (mg/L) }\end{array}$} & \multirow{3}{*}{$\begin{array}{l}\text { Nitrate } \\
(\mathrm{mg} / \mathrm{L})\end{array}$} & \multicolumn{2}{|c|}{ Nitrate Trend } & \multicolumn{2}{|c|}{ Predicted Nitrate in 2040} \\
\hline & & & & & & & & Slope $^{1}$ & $\mathbf{R}^{2}$ & & $>\mathrm{MCL}$ \\
\hline & & & & & & & & (mg/L/year) & & $(\mathrm{mg} / \mathrm{L})$ & $95 \%$ conf. level \\
\hline 8 & 21.4 & 4.3 & 5.7 & 20.3 & 11.1 & 9.5 & 22.6 & 0.65 & 0.93 & 38.8 & no \\
\hline 39 & 24.0 & 4.1 & 5.3 & 22.5 & 11.5 & 10.0 & 29.1 & 0.79 & 0.82 & 48.8 & no \\
\hline 20 & 22.7 & 3.3 & 6.0 & 23.6 & 9.0 & 8.0 & 18.0 & 0.56 & 0.84 & 34.6 & no \\
\hline 29 & 24.6 & 3.5 & 5.5 & 21.4 & 14.5 & 6.3 & 15.0 & -0.30 & 0.11 & 4.4 & no \\
\hline 36 & 73.9 & 6.2 & 14.6 & 42.5 & 160.0 & 1.8 & 1.1 & - & 0.05 & 5.8 & no \\
\hline 14 & 26.2 & 3.4 & 10.7 & 35.8 & 12.3 & 17.4 & 32.2 & 0.69 & 0.69 & 47.9 & no \\
\hline 4 & 26.1 & 2.9 & 7.0 & 29.9 & 13.2 & 14.9 & 32.5 & 0.92 & 0.84 & 54.9 & yes \\
\hline 35 & 28.3 & 2.9 & 6.3 & 33.0 & 12.3 & 16.9 & 27.4 & 1.73 & 0.83 & 78.2 & yes \\
\hline 32 & 28.6 & 4.5 & 8.2 & 32.2 & 16.6 & 18.0 & 37.9 & 0.98 & 0.94 & 60.5 & yes \\
\hline
\end{tabular}

${ }^{1}$ : Slopes of trends in nitrate concentrations that are significant at the $5 \%$ level. 
Table 4: Measurements: Nitrate Isotopes and Dissolved Gases

\begin{tabular}{cccccccc}
\hline Well & $\begin{array}{c}\boldsymbol{\delta}^{15} \mathbf{N}- \\
\mathbf{N O}_{\mathbf{3}} \\
(\%)\end{array}$ & $\begin{array}{c}\boldsymbol{\delta}^{\mathbf{1 8}} \mathbf{O} \\
\mathbf{N O}_{\mathbf{3}} \\
(\%)\end{array}$ & $\begin{array}{c}\mathbf{N}_{\mathbf{2}} \\
\left(10^{-3} \mathrm{~cm}^{3} \mathrm{STP} / \mathrm{g}\right)\end{array}$ & $\begin{array}{c}\mathbf{O}_{\mathbf{2}} \\
\left(10^{-3} \mathrm{~cm}^{3} \mathrm{STP} / \mathrm{g}\right)\end{array}$ & $\begin{array}{c}\text { Ar } \\
\left(10^{-3} \mathrm{~cm}^{3} \mathrm{STP} / \mathrm{g}\right)\end{array}$ & $\begin{array}{c}\text { Excess } \mathbf{N}_{\mathbf{2}} \\
\left(10^{-3} \mathrm{~cm}^{3} \mathrm{STP} / \mathrm{g}\right)\end{array}$ & \pm \\
\hline 8 & 6.0 & 1.8 & 13.7 & 5.45 & 0.338 & $<$ & 1.0 \\
39 & 7.1 & 2.0 & 13.9 & 4.18 & 0.342 & $<$ & 1.0 \\
20 & 5.1 & 0.6 & 14.3 & 4.08 & 0.356 & $<$ & 1.1 \\
29 & 6.4 & 1.3 & 14.3 & 4.27 & 0.346 & $<$ & 1.1 \\
36 & 5.5 & 5.2 & 20.1 & 3.19 & 0.380 & 3.5 & 0.8 \\
14 & 6.1 & 1.2 & 15.5 & 4.63 & 0.381 & $<$ & 1.2 \\
4 & 6.9 & 0.7 & 15.3 & 2.42 & 0.363 & $<$ & 1.1 \\
35 & 4.6 & -0.1 & 15.6 & 2.22 & 0.365 & $<$ & 1.1 \\
32 & 8.4 & 1.8 & & & & & $<$ \\
\hline
\end{tabular}


Table 5: Measurements: ${ }^{85} \mathrm{Kr}$

\begin{tabular}{|c|c|c|c|c|c|c|c|c|}
\hline Well & $\begin{array}{l}\text { LLNL } \\
\mathrm{dpm} / \mathrm{cm}^{3} \mathrm{Kr}\end{array}$ & \pm & $\%$ modern & \pm & $\begin{array}{l}\text { Bern } \\
\mathrm{dpm} / \mathrm{cm}^{3} \mathrm{Kr}\end{array}$ & \pm & $\%$ modern & \pm \\
\hline 8 & $<$ & 6.7 & $<$ & 9 & 4.8 & 1.7 & 6.4 & 2.3 \\
\hline 39 & $<$ & 4.9 & $<$ & 7 & 6.6 & 1.3 & 8.8 & 1.7 \\
\hline 20 & $<$ & 7.7 & $<$ & 10 & 6.4 & 1.3 & 8.5 & 1.7 \\
\hline 29 & $<$ & 5.4 & $<$ & 7 & 2.2 & 1.7 & 2.9 & 2.3 \\
\hline 36 & $<$ & 6.3 & $<$ & 8 & $<$ & 17.0 & $<$ & 24.0 \\
\hline 14 & $<$ & 10.2 & $<$ & 14 & 1.5 & 1.3 & 2.0 & 1.7 \\
\hline \multicolumn{9}{|l|}{4} \\
\hline \multicolumn{9}{|l|}{35} \\
\hline 32 & & & & & & & & \\
\hline
\end{tabular}


Table 6: Measurements: Noble Gas Derived Parameters

\begin{tabular}{cccccc}
\hline Well & $\begin{array}{c}\text { Excess Air } \\
\Delta \text { Ne }\end{array}$ & \multicolumn{2}{c}{$\begin{array}{c}\text { Noble Gas Recharge } \\
\text { Temperature }\end{array}$} & \multicolumn{2}{c}{$\begin{array}{c}\text { Geothermal } \\
\text { Warming }\end{array}$} \\
& $25 \%$ & $\left({ }^{\circ} \mathrm{C}\right)$ & \pm & $\left({ }^{\circ} \mathrm{C}\right)$ & \pm \\
\hline 8 & $20 \%$ & 18.3 & 1.0 & 3.7 & 1.0 \\
39 & $21 \%$ & 18.4 & 1.7 & 2.8 & 1.7 \\
20 & $23 \%$ & 17.5 & 1.6 & 3.9 & 1.6 \\
29 & $43 \%$ & 16.1 & 1.6 & 5.6 & 1.6 \\
36 & $36 \%$ & 14.6 & 1.0 & 9.2 & 1.0 \\
14 & $36 \%$ & 17.5 & 1.0 & 3.7 & 1.0 \\
4 & $37 \%$ & 17.4 & 1.0 & 3.5 & 1.0 \\
35 & $39 \%$ & 17.8 & 1.0 & 2.9 & 1.1 \\
32 & & 17.4 & 1.0 & 3.9 & 1.0 \\
\hline
\end{tabular}


Table 7: Measurements: Tritium and Helium Isotopes

\begin{tabular}{|c|c|c|c|c|c|c|c|c|c|c|}
\hline Well & $\begin{array}{c}{ }^{3} \mathbf{H} \\
(\mathrm{pCi} / \mathrm{L}) \\
\end{array}$ & \pm & $\begin{array}{c}\text { Tritiogenic } \\
{ }^{3} \mathrm{He} \\
(\mathrm{pCi} / \mathrm{L})\end{array}$ & \pm & $\begin{array}{c}{ }^{3} \mathrm{H} /{ }^{3} \mathrm{He} \\
\text { Age } \\
(\mathrm{yr})\end{array}$ & \pm & (pCi/L) & ${ }^{3} \mathrm{H}$ & $\begin{array}{c}\text { Terrigenic } \\
{ }^{4} \mathrm{He} \\
\left(10^{-9} \mathrm{~cm}^{3} \mathrm{STP} / \mathrm{g}\right)\end{array}$ & \pm \\
\hline 8 & 2.02 & 0.35 & 46.9 & 13.4 & 56.7 & 5.7 & 49.0 & 13.4 & 209 & 6 \\
\hline 39 & 2.99 & 0.38 & 36.0 & 8.0 & 47.1 & 4.5 & 42.4 & 9.4 & 83 & 3 \\
\hline 20 & 2.46 & 0.32 & 6.6 & 9.3 & 23.2 & 18.3 & 9.1 & 9.3 & 127 & 4 \\
\hline 29 & 1.94 & 0.36 & 41.0 & 21.4 & 55.0 & 9.4 & 42.9 & 21.4 & 403 & 9 \\
\hline 36 & 0.19 & 0.36 & & & & & & & 4012 & 82 \\
\hline 14 & 6.08 & 0.48 & 53.6 & 9.7 & 40.6 & 3.1 & 59.7 & 9.7 & 56 & 3 \\
\hline 4 & 5.32 & 0.48 & 55.3 & 17.2 & 43.2 & 5.2 & 60.6 & 17.2 & 273 & 7 \\
\hline 35 & 4.84 & 0.38 & 57.7 & 10.6 & 49.3 & 17.8 & 61.5 & 11.3 & 79 & 4 \\
\hline 32 & 4.42 & 0.55 & 35.3 & 11.4 & 39.1 & 5.5 & 39.8 & 11.4 & 161 & 5 \\
\hline
\end{tabular}


Table 8: Measurements: Carbon Isotopes

\begin{tabular}{cccccc}
\hline Well & $\begin{array}{c}\text { Total Inorganic Carbon } \\
(\mathrm{mg} / \mathrm{L})\end{array}$ & $\begin{array}{c}\boldsymbol{\delta}^{\mathbf{1 3}} \mathbf{C} \\
(\%)\end{array}$ & \pm & $\begin{array}{c}{ }^{14} \mathbf{C} \\
\text { (fraction modern) }\end{array}$ & \pm \\
\hline 8 & 24.3 & -14.7 & 0.4 & 0.387 & 0.002 \\
39 & 24.6 & -14.6 & 0.6 & 0.380 & 0.002 \\
20 & 29.1 & -14.5 & 2.6 & 0.355 & 0.002 \\
29 & 27.3 & -14.8 & 0.0 & 0.309 & 0.002 \\
36 & 29.4 & -28.6 & 0.1 & 0.047 & 0.001 \\
14 & 36.3 & -14.6 & 0.1 & 0.758 & 0.003 \\
4 & 29.1 & -15.2 & 0.4 & 0.560 & 0.002 \\
35 & 32.4 & -14.5 & 0.1 & 0.578 & 0.002 \\
32 & 30.2 & -14.9 & 0.5 & 0.486 & 0.002 \\
\hline
\end{tabular}


Table 9: Correlation coefficient between ensemble $(n=1000)$ of modeled tracer concentrations and measurements.

\begin{tabular}{lccc}
\hline Tracer & $\begin{array}{c}\text { Scenario 1 } \\
\text { nitrate+tracers }\end{array}$ & $\begin{array}{c}\text { Scenario 2 } \\
\text { nitrate only }\end{array}$ & $\begin{array}{c}\text { Scenario 3 } \\
\text { tracers only }\end{array}$ \\
\hline${ }^{3} \mathrm{H}$ & 0.64 & 0.29 & 0.73 \\
${ }^{3} \mathrm{He}$ & 0.08 & 0.10 & 0.36 \\
${ }^{13} \mathrm{C}$ & 0.00 & 0.77 & 0.11 \\
${ }^{14} \mathrm{C}$ & 0.01 & 0.54 & 0.63 \\
${ }^{4} \mathrm{He}$ & 0.04 & 0.50 & 0.71 \\
${ }^{85} \mathrm{Kr}$ & 0.14 & 0.05 & 0.89 \\
$\mathrm{NO}_{3}$ & 0.72 & 0.72 & 0.17 \\
\hline
\end{tabular}


Table 10: Probability that nitrate concentrations exceed the MCL $(45 \mathrm{mg} / \mathrm{L})$ in 2040 .

\begin{tabular}{lccc}
\hline Tracer & $\begin{array}{c}\text { Scenario 1 } \\
\text { nitrate+tracers }\end{array}$ & $\begin{array}{c}\text { Scenario 2 } \\
\text { nitrate only }\end{array}$ & $\begin{array}{c}\text { Scenario 3 } \\
\text { tracers only }\end{array}$ \\
\hline 8 & $0 \%$ & $8 \%$ & $0 \%$ \\
39 & $0 \%$ & $0 \%$ & $0 \%$ \\
20 & $0 \%$ & $0 \%$ & $0 \%$ \\
29 & $0 \%$ & $0 \%$ & $0 \%$ \\
14 & $9 \%$ & $25 \%$ & $0 \%$ \\
4 & $4 \%$ & $53 \%$ & $0 \%$ \\
35 & $100 \%$ & $85 \%$ & $0 \%$ \\
32 & $95 \%$ & $100 \%$ & $0 \%$ \\
\hline
\end{tabular}

